\title{
Chronic adiponectin deficiency leads to Alzheimer's disease-like cognitive impairments and pathologies through AMPK inactivation and cerebral insulin resistance in aged mice
}

Roy Chun-Laam Ng ${ }^{1,4}$, On-Yin Cheng 1,4, Min Jian', Jason Shing-Cheong Kwan 1,4, Philip Wing-Lok Ho 1,2, Kenneth King-Yip Cheng ${ }^{1,2}$, Patrick Ka Kit Yeung ${ }^{5}$, Lena Lei Zhou', Ruby Lai-Chong Hoo ${ }^{1,2}$, Sookja Kim Chung ${ }^{2,3,5}$, Aimin $\mathrm{Xu}^{1,2}$, Karen Siu-Ling. Lam ${ }^{1,2,3,6^{*}}$ and Koon Ho Chan ${ }^{1,2,3,4,6^{*}}$

\begin{abstract}
Background: Insulin resistance is the major pathogenesis underlying type 2 diabetes mellitus (T2DM) and these patients have doubled risk of Alzheimer's disease (AD). Increasing evidence suggests that insulin resistance plays an important role in AD pathogenesis, possibly due to abnormal GSK3 $\beta$ activation, causing intra- and extracellular amyloid-beta (Aß) accumulation. Adiponectin (APN) is an adipokine with insulin-sensitizing and anti-inflammatory effects. Reduced circulatory APN level is associated with insulin resistance and T2DM. The role of APN in AD has not been elucidated. In this study, we aim to examine if adiponectin deficiency would lead to cerebral insulin resistance, cognitive decline and Alzheimer's-like pathology in mice.
\end{abstract}

Methods: To study the role of adiponectin in cognitive functions, we employed adiponectin-knockout (APN-KO) mice and demonstrated chronic APN deficiency in their CNS. Behavioral tests were performed to study the cognitions of male APN-KO mice. Brains and tissue lysates were collected to study the pathophysiological and molecular changes in the brain of APN-KO mice. SH-SY5Y neuroblastoma cell line was used to study the molecular mechanism upon APN and insulin treatment.

Results: Aged APN-deficient mice displayed spatial memory and learning impairments, fear-conditioned memory deficit as well as anxiety. These mice also developed AD pathologies including increased cerebral $A \beta_{42}$ level, $A \beta$ deposition, hyperphosphorylated Tau proteins, microgliosis and astrogliosis with increased cerebral IL-1 $\beta$ and TNFa levels that associated with increased neuronal apoptosis and reduced synaptic proteins levels, suggesting APN deficiency may lead to neuronal and synaptic loss in the brain. AD pathologies-associated APN-KO mice displayed attenuated AMPK phosphorylation and impaired insulin signaling including decreased Akt induction and increased GSK3 $\beta$ activation in the hippocampus and frontal cortex. Aged APN-KO mice developed hippocampal insulin resistance with reduced pAkt induction upon intracerebral insulin injection. Consistently, APN treatment in SH-SY5Y cells with insulin resistance and overexpressing $A \beta$ induce higher pAkt levels through AdipoR1 upon insulin treatment whereas the induction was blocked by compound C, indicating APN can enhance neuronal insulin sensitivity through AMPK activation. (Continued on next page)

\footnotetext{
* Correspondence: ksllam@hku.hk; koonho@hkucc.hku.hk

'Department of Medicine, LKS Faculty of Medicine, The University of Hong

Kong, Hong Kong, Special Administrative Region, China

Full list of author information is available at the end of the article
} 
(Continued from previous page)

Conclusion: Our results indicated that chronic APN deficiency inactivated AMPK causing insulin desensitization and elicited AD-like pathogenesis in aged mice which also developed significant cognitive impairments and psychiatric symptoms.

Keywords: Adiponectin, Alzheimer's disease, Insulin resistance, A $\beta$, AMPK, Cognitive impairments

\section{Background}

Alzheimer's disease (AD) is the most common cause of dementia in the elderlies. AD brain pathologies are characterized by deposition of extracellular amyloid- $\beta$ (A $\beta$ )-containing senile plaques, intracellular hyperphosphorylated Tau-containing neurofibrillary tangles (NFT), neuroinflammation, synaptic loss and neuronal death, leading to cognitive impairments. Aging and apolipoprotein $\mathrm{E} \varepsilon 4$ allele are known risk factors. Recently, type 2 diabetes mellitus (T2DM) is recognized as another risk factor of AD. Accumulating evidence demonstrated that T2DM and AD share similar pathophysiologies such as insulin resistance, disrupted glucose and lipid metabolism, inflammation and oxidative stress [1-5].

Cerebral insulin resistance is increasingly recognized as an important factor of $\mathrm{AD}$ pathogenesis. A series of studies has shown a strong association between insulin signaling and $A \beta$ metabolism. Notably, $A \beta$ oligomers, including dimers, trimers and dodecamers $(\mathrm{A} \beta * 56)$, are the early neurotoxic species in AD. Cerebral insulin resistance results in glycogen synthase kinase $3 \beta$ (GSK3 $\beta$ ) activation, leading to increased $A \beta$ production and Tau phosphorylation [6-8]. It was reported that insulin resistance increased extracellular $A \beta$ deposition by enhancing $\gamma$-secretase activity, which is involved in $A \beta$ production, thereby promoting $A \beta$ secretion from neurons [9]. In contrast, insulin inhibits the GSK3 $\beta$ activity to prevent generation of $A \beta$ and hyperphosphorylated Tau $[8,10]$. Studies using transgenic AD mice models revealed that the transgenic mice exhibited hippocampal insulin resistance [11]. Leptin-deficient mice, a T2DM model, displayed impaired cerebral insulin signaling and cognitive impairments after treating with high-fat-diet $[12,13]$. Postmortem study of $\mathrm{AD}$ brains indicated significant increase of insulin receptor substrate-1 (IRS1) phosphorylation at serine residues, marker of insulin resistance. In addition, insulin resistance is associated with impaired synaptic plasticity [14]. Insulin administration reduced chronic neuroinflammation and microglia activation as well as enhanced synapse formation in $\mathrm{AD}$ mouse model $[15,16]$. These studies established the associations between $\mathrm{AD}$, cerebral insulin resistance and T2DM.

Adiponectin (APN) is an adipocyte-secreted circulating hormone, which exerts insulin sensitizing, antiinflammatory and anti-oxidative effects to peripheral tissues. APN exists in three oligomeric forms in circulation, including trimers, hexamers and high molecular weight (HMW) oligomers [17]. T2DM patients and aged individuals have reduced circulating APN levels [18]. APN deficiency is associated with peripheral insulin resistance in mice and human, causing T2DM and DM-related syndromes $[19,20]$, whereas whether adiponectin is associated with cerebral insulin sensitivity has not been documented. Studies indicated APN can ameliorate insulin sensitivity by enhancing AMPactivated protein kinase (AMPK) phosphorylation, thereby, activating insulin receptor substrate (IRS) phosphorylation at Tyrosine residues. This promotes insulin signaling activities including insulin-mediated cell survival by inhibiting GSK3 $\beta$ and glucose uptake by enhancing translocation of GLUT4 transporter [21, 22].

The role of APN in the central nervous system (CNS) is not well characterized. Adiponectin receptors (AdipoR1 \& AdipoR2) are abundantly expressed in the hippocampus, cortex and hypothalamus [23, 24]. Only trimeric and hexameric APN are detectable in human cerebrospinal fluid (CSF) suggesting that low molecular weight APN can cross the blood-brain barrier (BBB) and has a role in CNS [25]. APN has shown to be important in neurogenesis and proliferation of hippocampal neural stem cells [26, 27]. It has also been reported that APN-deficient mice exhibited depressive-like behavior [23]. Physical activities and environmental enrichment can increase cerebral APN levels that exerted anti-depressive effects and reduced neuroinflammation in mice [27]. Loss of APN in mice also exacerbated the severity of encephalomyelitis by activating lymphocytes in the mouse model of multiple sclerosis [28]. Clinical reports revealed association between decreased APN levels and ischemic stroke. APN treatment in mice with cerebral ischemia improved neurobehavioral performance and focal cerebral neurogenesis [29]. T2DM patients with lower serum APN levels have a lower mean hippocampal volume than T2DM patients with normal adiponectin levels [30]. Our previous findings demonstrated APN to be protective against $A \beta$ neurotoxicity [31]. Although a recent publication showed an association between APN gene polymorphism and late onset AD [32], there are contradictory clinical reports on the difference of plasma APN level between non-demented control and AD or mild cognitive impairment patients [33-35]. The role of $\mathrm{APN}$ in $\mathrm{AD}$ remains uncertain. We, therefore, investigated if chronic APN deficiency would result in 
cerebral insulin resistance which is associated with ADlike pathologies, and cognitive impairments in aging mice.

In this study, we employed adiponectin knockout (APN-KO) mice to mimic the condition of chronic APN deficiency in T2DM patients and aged subjects, and demonstrated that there were cerebral insulin resistance and deregulated insulin signaling upon APN deficiency. The mice also exhibited memory decline and anxiety associated with $\mathrm{AD}$ pathologies including increased $\mathrm{A} \beta$ production, Tau phosphorylation, neuroinflammation and neurodegeneration. Our study provides novel evidence on the role of adiponectin in cerebral insulin sensitivity, development of AD-like pathologies and cognitive impairment.

\section{Results}

\section{Chronic APN deficiency in CNS of APN-KO Mice}

Trimeric APN could cross the BBB [27]. Recent studies showed that mRNA of adiponectin receptors were expressed in mouse brain. We performed immunofluorescent staining of AdipoR1 confirming that AdipoR1 protein is expressed in the cortex and hippocampus of mouse (Additional file 1). This indicated that the brain can respond to adiponectin present in the CNS. To verify if endogenous APN is present in WT mice and absent in APN-KO mice, the concentration of APN in CSF was determined by semi-quantitative dot-blot immunoassay. With reference to the standard curve (Additional file 1), concentrations of APN in CSF of 18-mth old WT mice were $428 \mathrm{ng} / \mathrm{mL} \pm 156 \mathrm{ng} / \mathrm{mL} \quad(n=4, p<0.05)$, whereas APN was undetectable in the CSF of aged APN-KO mice (Additional file 1). The APN-KO mice had chronic deficiency of APN, not only in peripheral tissues, but also in the CNS.

\section{Aged APN-KO mice had anxiety, and impaired spatial learning and memory loss}

To evaluate if psychiatric symptoms may be related to APN deficiency in aged individuals, we performed open field test to investigate the anxiety level in APN-KO mice. Both 9-mth-old \& 18-mth-old APN-KO spent significantly longer time in the margin area and shorter time in the center area $(14.05 \% \pm 2.28 \%$ in 9-mth-old WT mice vs $7.34 \% \pm 2.19 \%$ in 9 -mth-old APN-KO mice, Fig. 1a; $15.99 \% \pm 1.43 \%$ in 18 -mth-old WT mice vs $10.32 \% \pm 1.41 \%$ in 18 -mth-old APN-KO mice, mean \pm S.E.M, $p<0.05$, Fig. $1 \mathrm{~b}$ ), indicating that chronic APN deficiency in mice was associated with increased anxiety level.

To assess the spatial learning and memory abilities of aging APN-KO mice, we employed a hidden platform version of the Morris-Water-Maze. Time required to locate the hidden platform during acquisition phase was analyzed. In the test, mice were trained with visible platform so that they could learn to locate the platform. The visible platform tests showed that both WT and APN$\mathrm{KO}$ mice had a similar trend of escape latency in all 4 sessions $(p>0.05)$ by 9 -mths-of-age and 18-mths-of-age, suggesting that aging did not significantly affect the locomotor activity and vision in WT and APN-KO mice. 9-mth old APN-KO adult mice showed no significant spatial learning and memory impairment $(p>0.05$, Fig. 1c). However, we observed moderate prolongation in the latency of locating the hidden platform in 18-mth-old APN-KO mice. Although WT and APN-KO mice have had similar escape latency in the first two sessions, there were significant differences in the third and fourth sessions, suggesting that aged APN deficient mice had spatial memory and learning impairment $(p<0.05$, Fig. 1d), which was not due to differences in swim speed, visual acuity or locomotor deficits as demonstrated by visible platform test and swim speed recording (Additional file 2). In addition, the probe tests indicated that 9-mth old APN-KO mice spent comparable time in the target quadrant (compared with WT, $p>0.05$; Fig. 1e). In contrast, 18-mth-old APN-KO mice spent significantly less time in the target quadrant, suggesting there is a reference memory retention deficit in aged APN-KO mice $(p<0.05$, Fig. 1f). These results revealed that chronic APN deficiency in aged mice was associated with spatial learning and memory impairments.

Hence, the APN-KO mice had increased anxiety level. To further confirm that aged APN-KO mice suffered from learning and memory deficits, we performed contextual and cue fear-conditioning test, a stress-associated memory task, governed by hippocampus, amygdala and is cortical-associated. 12-mth old WT mice displayed robust contextual fear conditioning 1 day later with freezing $68.58 \% \pm 6.65 \%$. In contrast, 12 -mth old APN-KO mice froze significantly less $(14.68 \% \pm 3.08 \%$; $p<0.001$ versus WT mice; Additional file 3$)$. When the mice were placed in a novel environment and experienced with the same cue without shock, APN-KO mice also froze less than the WT mice $(51.71 \% \pm$ $4.99 \%$ in WT mice vs $30.29 \% \pm 3.93 \%$ in APN-KO mice; $p<0.05$, Fig. $1 \mathrm{~g} \&$ Additional file 4). These results provided further support that chronic APN deficiency was associated with impaired hippocampusdependent learning and memory upon aging.

\section{Aged APN-KO mice had AD-like brain pathologies}

To investigate if chronic APN deficiency could lead to increased $A \beta$ production and $A \beta$ oligomers, sections from 18-mth old wildtype and APN-KO mice were stained with antibody (clone 4G8) against $A \beta$. Faint $A \beta$ immunoreactive deposits were found in the cortex of APN-KO mice by 18 months but no plaque was present in the wildtype mice. ThioFlavin S staining also indicated the presence of $\mathrm{A} \beta$ deposits in $\mathrm{APN}-\mathrm{KO}$ mice by 


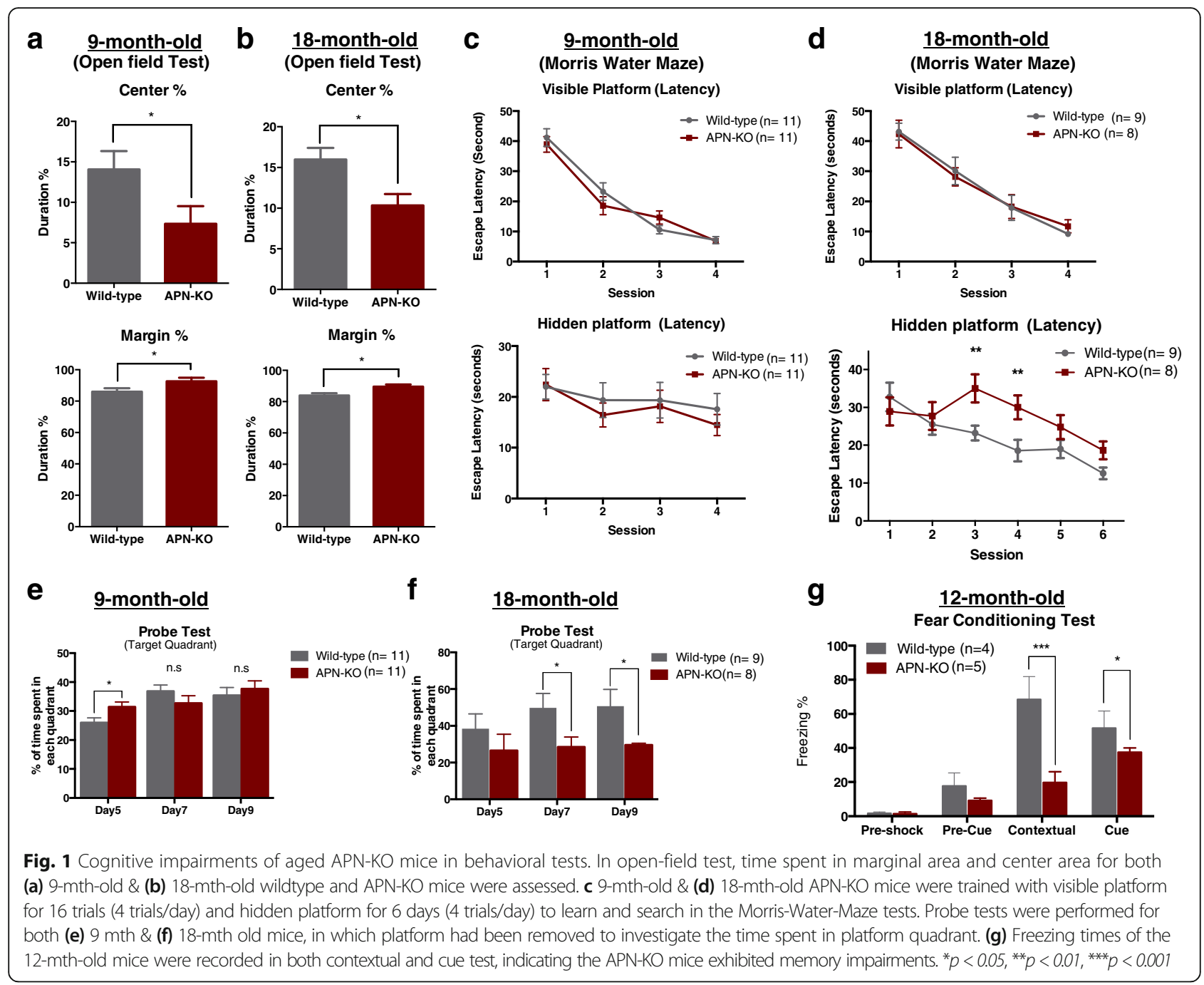

18 months-of-age (Fig. 2a). Levels of A 1-42 in WT and APN-KO mice were also determined by Sandwich ELISA. A $31-42$ levels in the hippocampus of 9-mth old APN-KO mice were comparable with that of WT mice (WT, $20.12 \pm 2.16 \mathrm{pg} / \mathrm{mg}$ of protein vs APN-KO, $21.06 \pm 8.96 \mathrm{pg} / \mathrm{mg}$ of protein; $p>0.05$ ) (Fig. 2a). Moreover, soluble A $\beta 1-42$ levels in the frontal cortex of 9-mth-old APN-KO mice were insignificantly higher than that of the WT mice (WT, $16.37 \pm 2.29 \mathrm{pg} / \mathrm{mg}$ of protein vs APN-KO, $19.06 \pm 2.08 \mathrm{pg} / \mathrm{mg}$ of protein; $p>0.05$ ) (Fig. 2b). However, $\mathrm{A} \beta 1-42$ levels were significantly increased in both the hippocampus (WT, $13.45 \pm 2.87 \mathrm{pg} / \mathrm{mg}$ of protein vs APN-KO, $46.77 \pm$ $11.58 \mathrm{pg} / \mathrm{mg}$ of protein; $p<0.05$ ) and frontal cortex (WT, $16.15 \pm 3.52 \mathrm{pg} / \mathrm{mg}$ of protein vs APN-KO, $58.41 \pm 16.67 \mathrm{pg} / \mathrm{mg}$ of protein; $p<0.05)$ of APN-KO mice relative to the wildtype mice by 18 month (Fig. 2b). In addition, we performed western blot by using 4G8 antibody to further verify the presence of $\mathrm{A} \beta$ oligomers in APN-KO mice. Interestingly, a distinct $56 \mathrm{kDa}$ band was detected in the hippocampal and frontal cortical lysate of APN-KO mice by 18 -month (Fig. 2c) but not by 9 -month old. A $\beta * 56$ is specific oligomeric species present in early $A D$ mice and aged human subjects [36, 37]. These results suggested that chronic APN deficiency in aged mice led to increased cerebral $A \beta$ accumulation.

To study whether Tau protein phosphorylation was increased in APN-KO mice, we evaluated the levels of $\mathrm{pTau}^{\mathrm{S} 199 / \mathrm{S} 202}$ \& $\mathrm{pTau}^{\mathrm{S} 396}$ in hippocampus and frontal cortex by western blot. Though Tau 5 (total tau) expression varied between the WT and APN-KO mice, results revealed that 18-month old APN-KO mice had increased Tau phosphorylation at both serine $e^{199 / 202}$ and serine ${ }^{396}$ in hippocampus and frontal cortex relative to that of wildtype mice (Fig. 2d).

AD-like neuroinflammation, increased neuronal apoptosis and reduction of synaptic proteins in aged APN-KO mice To determine if neuroinflammation was present in the brain of aged APN-KO mice, we initially examined 


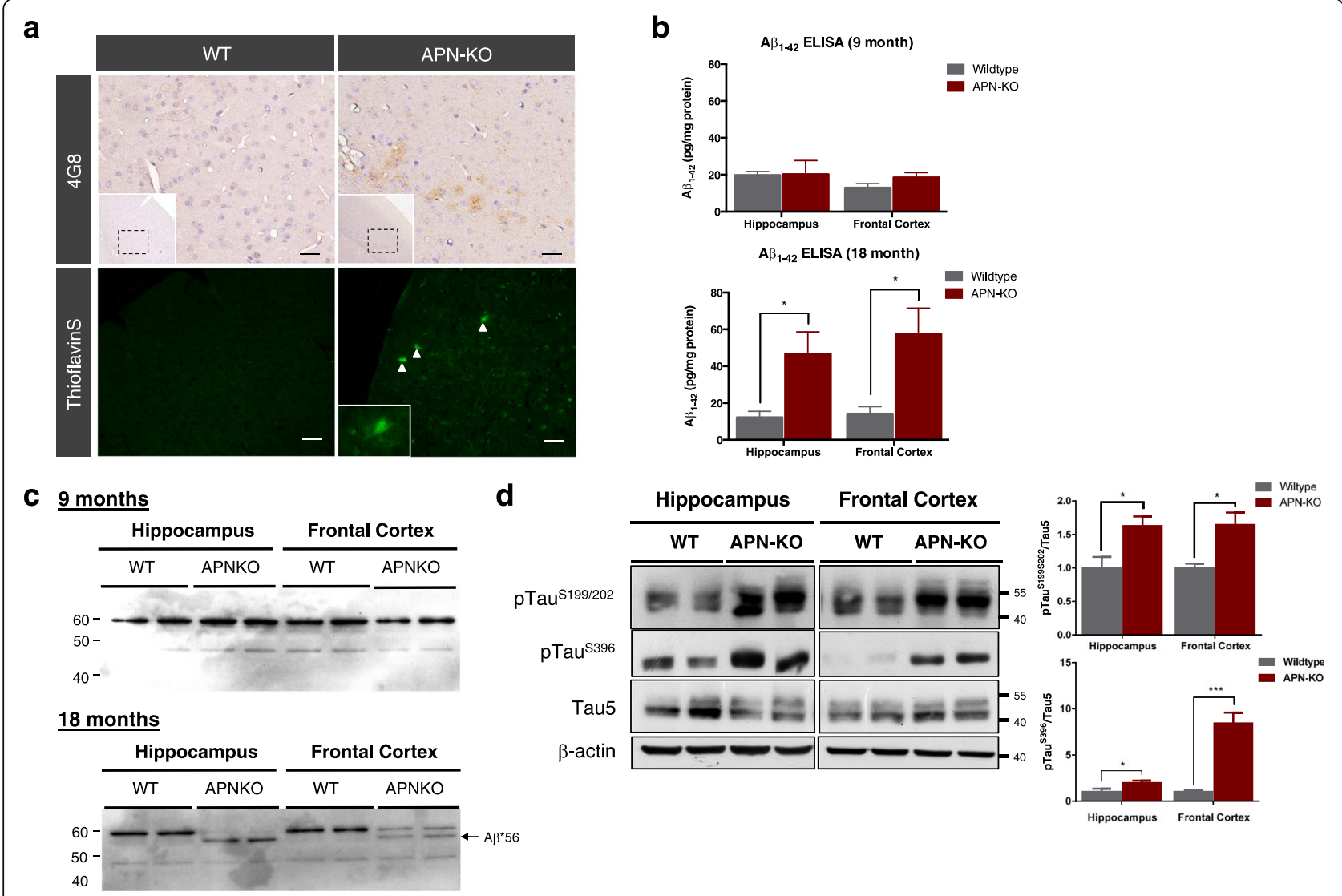

Fig. 2 Increase of A $\beta$ production and Tau phosphorylation in aged APN-KO mice. a Immunohistochemistry analysis of anti-A 3 (4G8) showed accumulation of $A \beta$ (Brown) in the cortex of 18-month APN-KO mice. $\mathbf{b}$ ELISA analysis of soluble $A \beta_{1-42}$ in the hippocampal and frontal cortical lysate of 9-month and 18-month old mice. $\mathbf{c}$ Immunoblotting of mouse $A \beta$ by antibody $4 \mathrm{G} 8$ showing the presence of $A \beta^{*} 56$ in the hippocampus and frontal cortex of 18-mth old APN-KO mice. $\mathbf{d}$ Immunoblotting of pTau serine ${ }^{199} \&^{202}$, pTau serine ${ }^{396}$ and Tau5 (total tau) in the hippocampus and frontal cortex of 18 -mth old mice. Mean \pm S.E.M.; ${ }^{*} p<0.05,{ }^{* *} p<0.01$, n.s. statistically not significant; WT $(n=4)$ vs APN-KO $(n=6)$. Scale bar: $50 \mu m$

changes of expression of Iba-1, a marker of microglia, in the cortex. Consistent with the robust inflammation reported in $\mathrm{AD}$ brains and $\mathrm{AD}$ mice model, higher number of Iba1-positive cells was observed in APN-KO by 18-mth (Fig. 3a). Astrogliosis is another pathological hallmark of $\mathrm{AD}$, we then performed immunohistochemistry staining of GFAP in the brain sections of aged APN-KO mice. The number of GFAP-immunoreactive astrocytes in the CA1 regions of the hippocampus was significantly increased and astrocytes displayed hypertrophic changes. Quantitative analysis was also performed to confirm an increase in the number of Iba-1-positive cells in APN-KO mice, as compared with the wildtype mice. Furthermore, quantitative analysis revealed that the percentage of the area occupied by GFAP-positive cells was increased in the hippocampus of the APN-KO mice compared with the wildtype mice (Fig. 3b). We subsequently studied the expression of MHCII, a marker of proinflammatory activation (M1) of microglia, by western blot. The substantial increase of MHCII expression in both frontal cortex and hippocampus of 18-month old APN-KO mice indicated that the mice had reactivation of microglia and chronic cerebral inflammation (Fig. 3c). Reactivated microglia secrete proinflammatory cytokines (e.g., TNF $\alpha$ \& IL-1 $\beta$ ) that can cause synaptic loss $[38,39]$. We then examined the cerebral levels of TNF $\alpha$ and IL-1 $\beta$ in APN-KO mice by ELISA assay. Both IL- $1 \beta$ and TNF $\alpha$ levels were increased in the aged APN-KO mice compared with wild-type mice of the same age (Fig. 3d). Together, these data suggested that APN deficiency led to neuroinflammation in aged mice.

To explore whether the cognitive impairments in aged APN-KO mice were associated with neurodegeneration, we evaluated neuronal apoptosis by double immunofluorescent staining of NeuN and TUNEL. Neuronal apoptotic cells in the hippocampus CA1 and cortex were markedly increased in aged APN-KO mice compared with wildtype mice (Fig. 4a). Quantitative analysis revealed that the estimated number of apoptotic cells in cortical defined regions in APN-KO was significantly higher than that of the wildtype mice $(214.0 \pm 26.2$ vs 

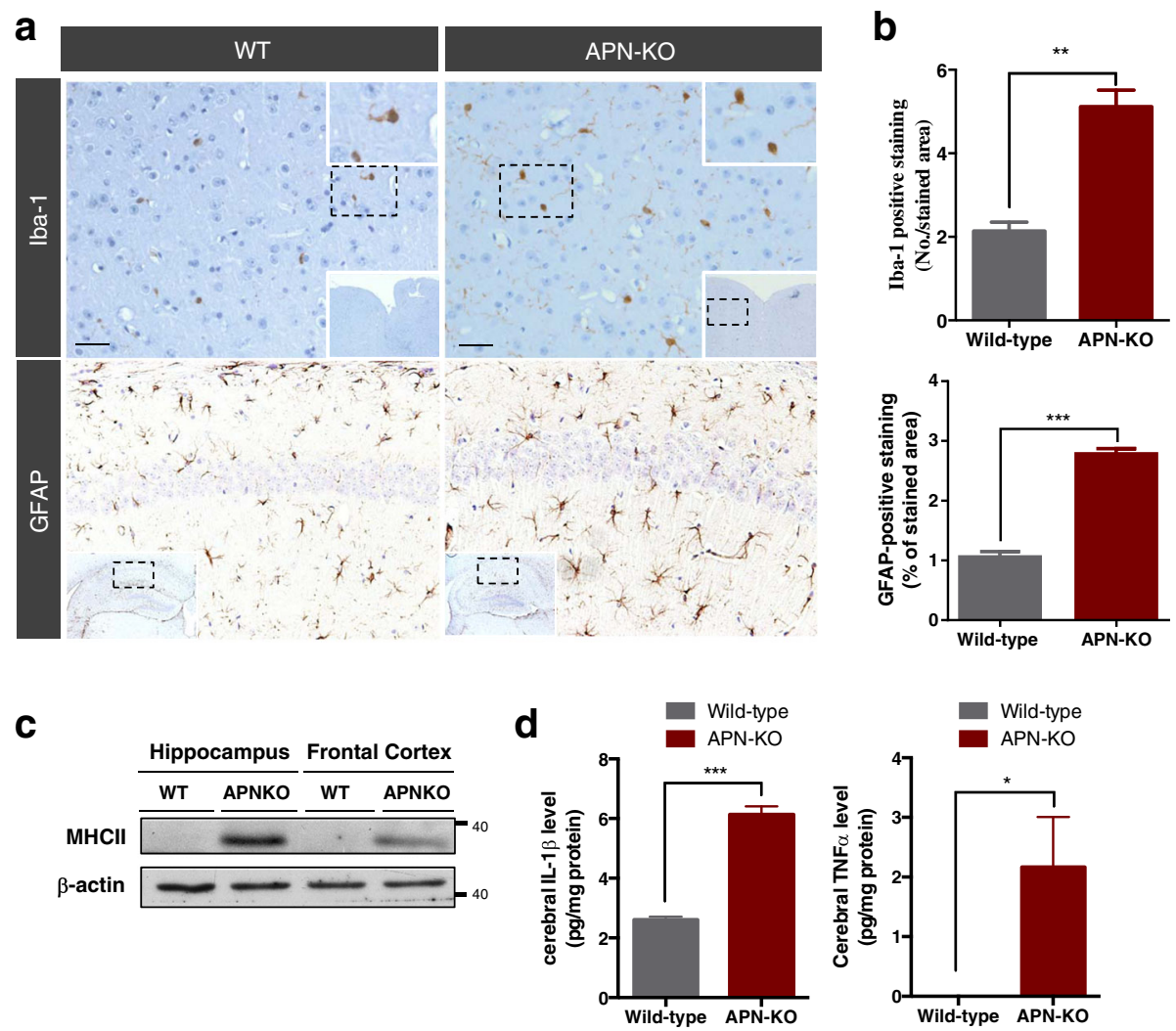

Fig. 3 Microglial reactivation and increased cerebral proinflammatory cytokines in APN-KO mice. a Representative image of immunohistochemistry staining of Iba-1 and GFAP represents the present of activated microglia (Brown, black arrows) and astrocytes respectively in the cortex of 18-mth old wildtype and APN-KO mice. $\mathbf{b}$ The percentage of Iba1 and GFAP positive stained area in the cortex of mice. c MHCll, M1 microglial activation marker, was detected in the frontal cortex and the hippocampus of APN-KO mice. $\mathbf{d}$ Cerebral IL-1 $\beta$ and TNFa levels detected by ELISA indicated significant increase in the 18-mth-old APN-KO mice. Mean \pm S.E.M.; ${ }^{*} p<0.05,{ }^{* *} p<0.01$, ${ }^{* * *} p<0.001$, n.s. statistically not significant; WT $(n=3)$ vs APN-KO $(n=3$ or 4$)$. Scale bar: $50 \mu$ m

$46.3 \pm 11.9 ; p<0.05)$. In addition, the number of apoptotic cells in hippocampal CA1 region was also dramatically higher in APN-KO mice $(44.0 \pm 7.6$ vs 11.3 $\pm 3.5 ; p<0.01$ ) than in wildtype mice, indicating that the number of apoptotic neurons was increased in APN-KO mice (Fig. 4b). To study whether the presence of $A \beta$ oligomers and increased proinflammatory cytokines in the APN-KO mice were associated with synaptic loss, we examined the levels of spinophilin (post-synaptic protein) and synaptophysin (pre-synaptic protein) which are the common synaptic markers used to determine synaptic density. Western blot analysis showed that the level of synaptophysin was reduced significantly in the hippocampus and frontal cortex whereas spinophilin was reduced in the hippocampus of the aged APN-KO mice (Fig. 4c \& d). Altogether these results suggested that chronic APN deficiency in CNS was associated with neuroinflammation and possibly led to neuronal apoptosis and synaptic loss. They provided an explanation for the cognitive impairments observed in the aged APN$\mathrm{KO}$ mice.

\section{Chronic APN deficiency led to attenuated AMPK} activation causing deregulated insulin signaling pathways and cerebral insulin resistance

In peripheral tissues, APN signaling leads to AMPK activation, which reduces IRS-1 phosphorylation at serine residues to enhance insulin sensitivity [22, 40, 41]. To assess if there are changes of cerebral AMPK activities and insulin signaling between aged WT and APN-KO mice, we performed Western blot analysis to study the protein levels of main effectors in AMPK and insulin signaling. We found that there was drastic decrease of AMPK phosphorylation at threonine 172 $\left(\mathrm{pAMPK}^{\mathrm{T} 172}\right)$ in the frontal cortex and hippocampus of younger APN-KO mice (9-mth-old; Fig. 5a). Though AMPK phosphorylation was reduced insignificantly in the frontal cortex of APN-KO mice by 18-month-of-age, pAMPK $^{\mathrm{T} 172}$ in the hippocampus was reduced significantly in APN-KO compared to aged WT mice (Fig. 5b). Concomitantly, pIRS-1 ${ }^{\mathrm{S} 616}$ level was increased in the frontal cortex of aged APN-KO mice (18-mth-old; Fig. 5c), indicating that chronic APN deficiency might 

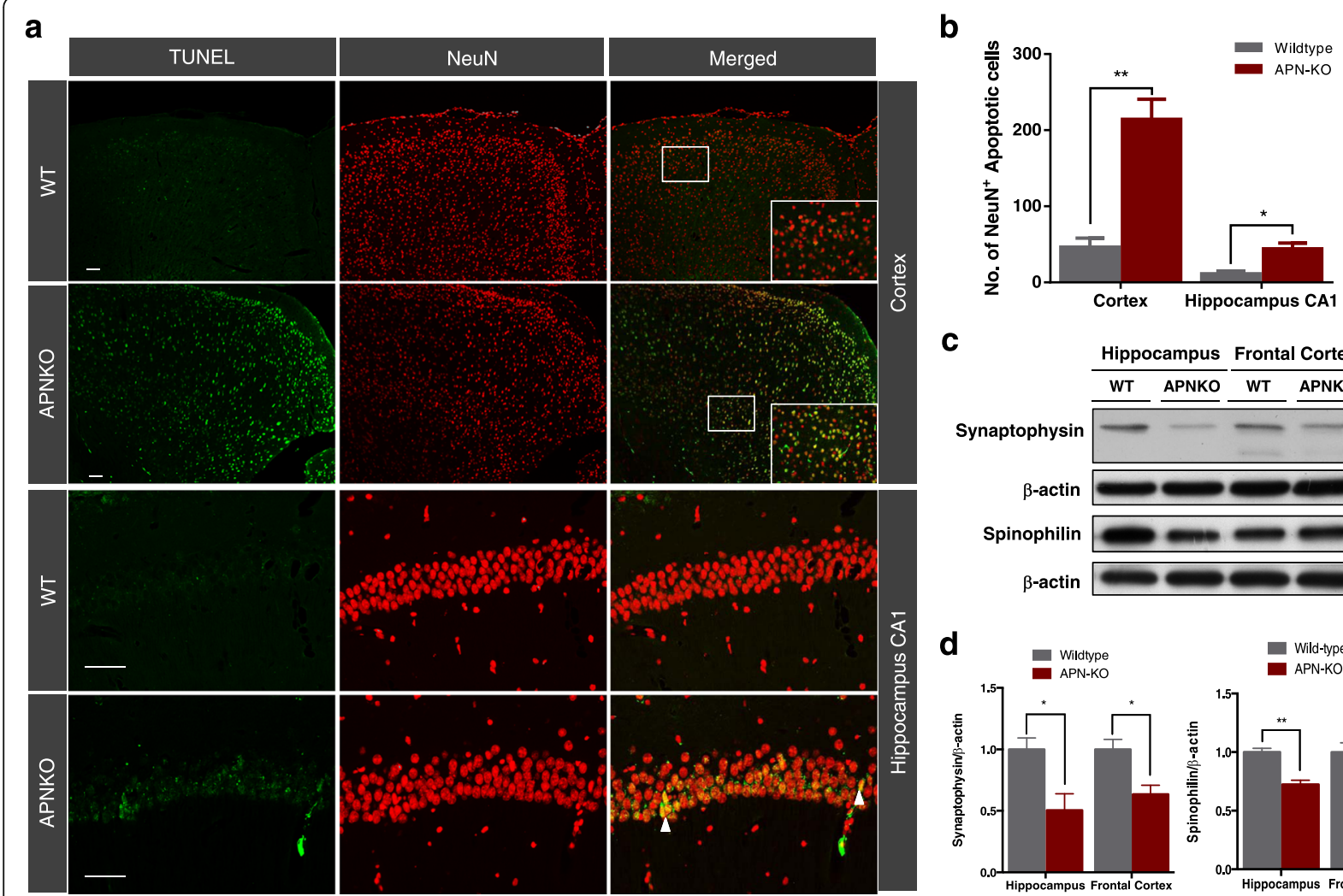

Fig. 4 Neuronal apoptosis and synaptic proteins reduction in 18-month old APN-KO mice. a Representative images show TUNEL-labeled (Red) apoptotic cells countered stained with DAPI (blue) in the cortex and hippocampus between 18-month old wildtype and APN-KO mice. b Graph demonstrates the differences of quantified numbers of TUNEL-labeled cells in the cortex and hippocampal CA1 region in wildtype and APN-KO mice. Two sampling regions (Blue square) in the cortex and one sampling region (red) in the hippocampal CA1 were defined. $\mathbf{c}$ Immunoblotting of synaptic proteins, synaptophysin and spinophilin in the hippocampus and frontal cortex of 18-mth old wildtype and APN-KO mice. $\mathbf{d}$ Densitometric analysis of synaptophysin and spinophilin demonstrating the differences of these synaptic proteins in the frontal cortex and hippocampus between wildtype and APN-KO mice. Mean \pm S.E.M.; ${ }^{*} p<0.05,{ }^{* *} p<0.01,{ }^{* * *} p<0.001$, n.s. statistically not significant; WT $(n=4)$ vs APN-KO $(n=4)$ Scale bar: $50 \mu \mathrm{m}$

lead to neuronal insulin resistance through inhibition of the AMPK-IRS1 signaling cascade.

pIRS-1 ${ }^{\text {S616 }}$ hinders the formation of activated form pIRS-1 ${ }^{\text {Tyr }}$, inactivating insulin signaling [6]. To examine whether chronic APN deficiency deregulated insulin signaling in neurons of aging mice, we performed western blotting to determine the level of phosphorylated Akt, GSK3 $\alpha / \beta$ and Erk1/2. The levels of $\mathrm{pAkt}^{\mathrm{S} 473}$, pGSK3 $\alpha^{\mathrm{S} 21}$ (inhibitory form of GSK3 $\alpha$ ) and $\mathrm{pGSK} 3 \beta^{\mathrm{S} 9}$ (inhibitory form of GSK3 $\beta$ ) were decreased while pGSK $3 \beta^{\mathrm{Y} 216}$ levels were drastically elevated in the frontal cortex and hippocampus of 9-mth-old APN-KO mice (Fig. 5d). We also found that level of pErk1/2 was reduced in both the frontal cortex and hippocampus of 9-mth old APN-KO mice, further indicating the disruption of insulin signaling (Additional file 5). In addition, there was no significant change in the level of insulin receptor (IR) suggesting that the reduced insulin signaling activities was not associated with reduced IR level (Additional file 6). Interestingly, the levels of IR, pAkt ${ }^{\mathrm{S} 473}$, pGSK3 $\alpha^{\mathrm{S} 21}$, pGSK3 $\beta^{\mathrm{S} 9}$ and pErk1/2 were increased significantly in the hippocampus of 18-mth-old APN$\mathrm{KO}$ mice but reduced in the frontal cortex compared to WT mice. pGSK3 $\alpha^{\mathrm{Y} 279} / \beta^{\mathrm{Y} 216}$ levels reduced insignificantly in the hippocampus between WT and APN-KO mice by 18-month old. However, the level of pGSK3 $\beta^{\mathrm{Y} 216}$ was higher in the frontal cortex of APN-KO mice (Fig. 5e, Additional file 5).

Since the endogenous plasma insulin level in APN-KO mice was comparable with the WT mice [42], the impaired insulin signaling activities may be due to changes in neuronal insulin sensitivity. To assess if there was changes in neuronal insulin sensitivity in aged APN-KO mice, we injected insulin ( $2 \mathrm{IU} / \mathrm{kg}$ body weight) to the right hippocampus of 12-mth-old APN-KO mice using a stereotaxic injection approach. We confirmed the position of injection by injecting a visible dye (Additional file 7). We found that induction of Akt activation after insulin injection to the right hippocampus was significantly reduced in the aged APN-KO mice compared to WT mice (Fig. 5f). The hippocampus of aged APN-KO mice was less sensitive to insulin compared to that of WT mice. 


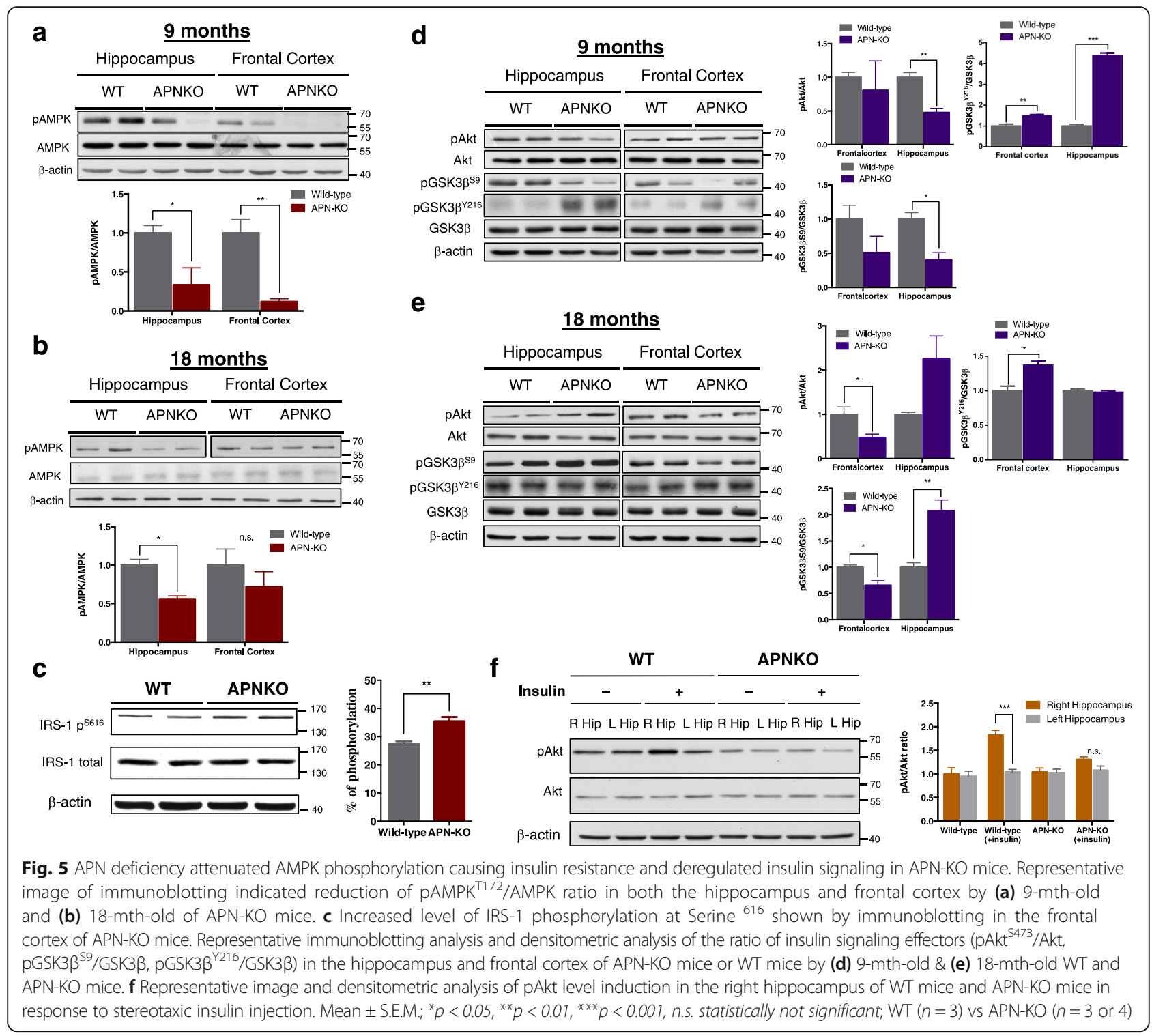

This indicated that chronic APN deficiency led to cerebral insulin resistance. Our results demonstrated that chronic APN deficiency was associated with cerebral insulin resistance and provided a possible molecular mechanism for the pathogenesis of AD in aged APN-KO mice.

\section{APN ameliorates neuronal insulin sensitivity through AdipoR1-mediated AMPK activation}

To study the insulin sensitization effect of APN in neuronal culture, human neuroblastoma SH-SY5Y cell line was induced with insulin resistance ( $\mathrm{SH}-\mathrm{SY}_{5} \mathrm{Y}_{\mathrm{IR}}$ ) by high concentration insulin. The pAkt level of SH-SY5Y IR cells did not increase after culturing with low concentration insulin $(10 \mathrm{nmol} / \mathrm{L})$ showing the presence of insulin resistance $(p>0.05)$. Mammalian trimeric APN restored the induction of pAkt and pGSK3 $\beta^{\mathrm{S} 9}$ levels in the
SH-SY5Y ${ }_{\text {IR }}$ cells with increased AMPK phosphorylation when cultured with $10 \mathrm{nmol} / \mathrm{L}$ insulin, demonstrating that APN could ameliorate neuronal insulin resistance. Furthermore, Compound C $(2 \mu \mathrm{M})$, an AMPK inhibitor, blocked the insulin sensitizing effect of adiponectin as pAkt and pGSK3 $\beta^{\mathrm{S} 9}$ levels were reduced in the SH-SY5Y IR cells (Additional file 8). This indicated that APN enhanced neuronal insulin sensitivity to inhibit GSK3 $\beta$ activity by activating AMPK signaling.

We further examined which adiponectin receptor was involved in APN-enhanced insulin sensitivity in $A \beta$-producing neurons and whether APN can reduce $A \beta$ production from neuronal cells. SH-SY5Y cells stably transfected with Swedish mutation of APP (SH-SY5Y $\left.{ }_{\text {swAPP }}\right)$ produced $\mathrm{A} \beta$ oligomers, mimicking the $\mathrm{AD}$ neurons, as we reported previously [31]. SH-SY5Y swAPP $_{\text {transfected with a }}$ 
combination of siAdipoR1 and siAdipoR2 had reduced expression of AdipoR1 and AdipoR2 respectively (Fig. 6a). AMPK phosphorylation was blocked in both cells transfected with AdipoR1 and AdipoR2 RNAi duplex upon APN treatment (Fig. 6b). Addition of insulin induced pAkt and $\mathrm{pGSK} 3 \beta^{\mathrm{S} 9}$ levels while addition of mammalian trimeric APN $(10 \mu \mathrm{g} / \mathrm{mL})$ further enhanced higher levels of pAkt and $\mathrm{pGSK} 3 \beta^{\mathrm{S9}}$ in SH-SY5Y $\mathrm{Y}_{\text {swAPP }}$ cells when cultured with $10 \mathrm{nmol} / \mathrm{L}$ insulin. This implicated that APN could also enhance insulin sensitivity in $A \beta$-overproducing neuroblastoma cells. However, the pAkt and pGSK3 $\beta^{\mathrm{Sg}}$ levels were not increased in AdipoR1-RNAi-transfected SH-SY5Y swAPP $_{\text {P }}$ when cultured with APN and insulin compared to the cells cultured with insulin only. In contrast, pAkt and pGSK3 $\beta^{\mathrm{S9}}$ levels were further enhanced upon APN plus insulin treatment in SH-SY5Y $Y_{\text {swAPP }}$ cells transfected with AdipoR2 RNAi (Fig. 6c). APN reduced extracellular A $\beta$ levels whereas the reduction was abrogated when SH-SY5Y cells were transfected with AdipoR1-RNAi. Interestingly, extracellular $A \beta$ levels were also reduced though nonsignificant in AdipoR2-RNAi-transfected cells upon APN treatment (Fig. 6d). These data suggested APN was effective in neuronal insulin-sensitization through AdipoR1-AMPK activation and could be a possible therapeutic agent in $\mathrm{AD}$.

\section{Discussion}

Our study demonstrated that aged mice with chronic APN deficiency in brain had spatial memory and fear-conditioned memory impairments as well as anxiety. Cognitive impairments in these aged mice were associated with $\mathrm{AD}$-like pathologies including increased $\mathrm{A} \beta$ oligomers and hyperphosphorylated Tau. In addition, neuroinflammation was also found in aged APN-KO mice, as evidenced by substantial microglial reactivation together with elevated proinflammatory cytokines (TNF $\alpha$ and IL-1 $\beta$ levels. Increased apoptosis and reduction of hippocampal synaptic proteins suggested neuronal and synaptic loss in the aged $\mathrm{APN}-\mathrm{KO}$ mice, which could be related to neurotoxic $\mathrm{A} \beta$ oligomers accumulation and elevated proinflammatory

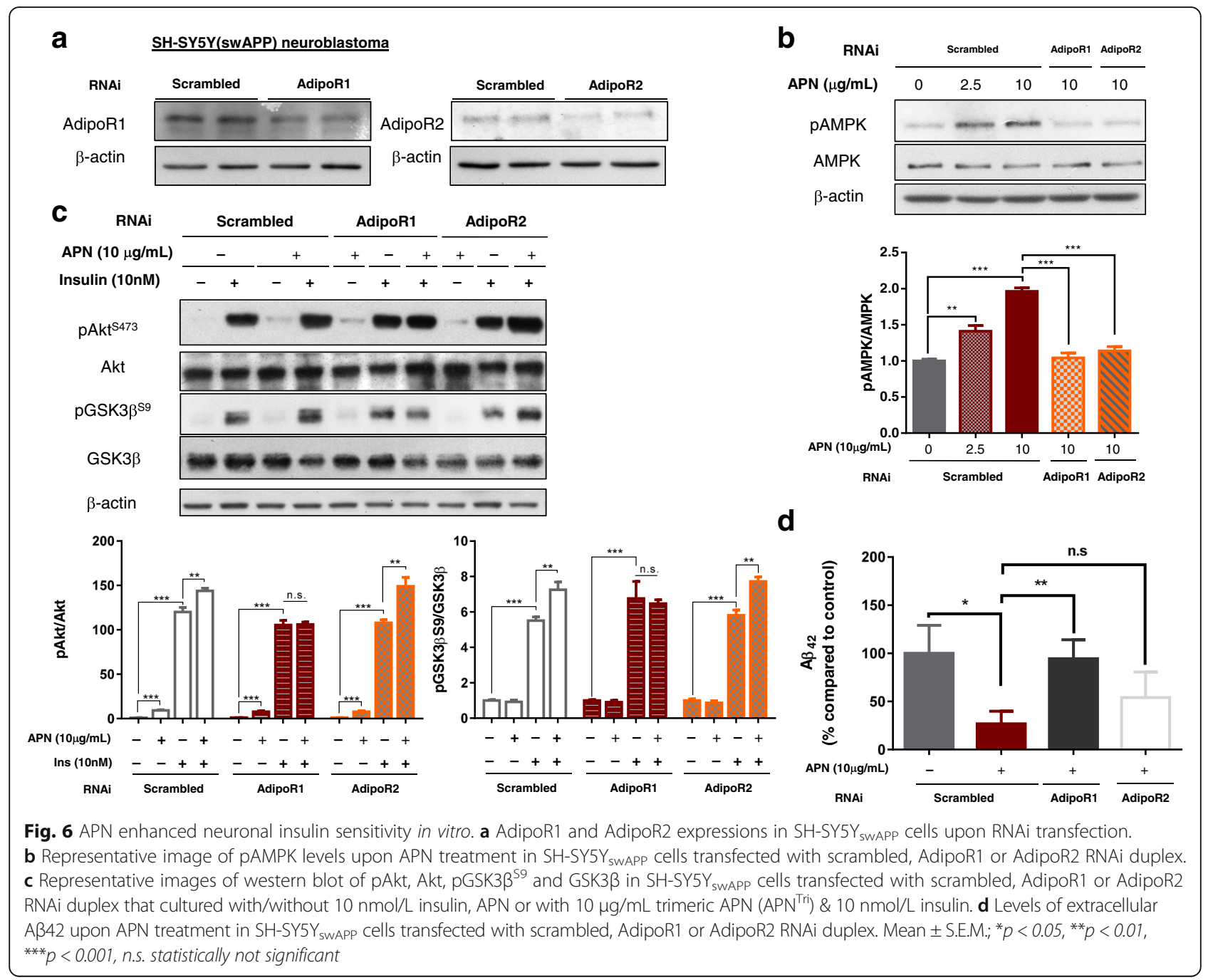


cytokines levels. Importantly, cerebral insulin resistance developed in the aged APN-KO mice with attenuated AMPK activation and impaired insulin signaling which was an underlying mechanism of $\mathrm{AD}$ pathogenesis. Concomitantly, our in vitro experiments showed that APN ameliorated neuronal insulin resistance. APN enhanced insulin sensitivity and reduced $A \beta$ production through AdipoR1-mediated AMPK activation. The role of APN in molecular signal of AD pathogenesis was proposed based on findings of the present study (Fig. 7). All these supported the cognitive impairments in APN-deficient mice were associated with cerebral insulin resistance, AD-like brain pathologies and mimicked the phenotypes of AD patients and rodent models.

Accumulating evidence suggests that insulin resistance and inflammation are involved in the pathogenesis of both T2DM and $\mathrm{AD}[6,39,43]$. Leptin, an adipokine has similar actions as APN in enhancing insulin sensitivity of peripheral tissues, has also been reported with neuroprotective effects. Leptin receptor-deficient mice, a T2DM model, had an age-dependent cognitive decline with reduced synaptic density and increased tau phosphorylation [13]. Despite that APN deficiency has a strong association with T2DM, the role of APN in AD is controversial. Considering the insulin sensitizing and antiinflammatory effects of APN in peripheral tissues, APN may exert neuroprotective effects against $A D$ pathogenesis. However, elevated plasma APN levels in AD patients were reported in some populations or specific gender $[33,44]$. Meanwhile, another clinical study demonstrated that decreased serum APN level is associated with mild cognitive impairments and AD [34]. A recent publication reported that polymorphisms in the APN gene locus were associated with higher risk of $\mathrm{AD}$ [32]. Although it is believed that APN crosses the $\mathrm{BBB}$ from the systemic circulation to the CNS, the changes of circulatory APN level may not reflect the changes of APN level in the CNS. Most importantly, there was no significant difference of CSF adiponectin between normal subjects and $\mathrm{AD}$ patients, indicating $\mathrm{AD}$ onset might not be associated with increased level of CSF APN [35]. Moreover, the changes in plasma APN level in AD could be either the cause or consequence of $\mathrm{AD}$ onset. To assess the consequence of the changes in protein level, a knockout animal would be a better approach. Therefore, we employed APN-KO mice as the model. The aged mice were provided with chow diet, normal social interaction, minimized stress environment as well as prolonged APN deficiency to mimic the condition in T2DM patients and elderly. We confirmed the absence of APN in CSF by dot-blot immunoassay. The aged APN-KO mice had spatial memory impairments and anxiety. Remarkably, the mice also displayed
AD-like pathologies including $\mathrm{A} \beta$ oligomers accumulation, Tau hyperphosphorylation, neuroinflammation and possibly synaptic loss. Our results suggested that chronic APN deficiency in CNS led to cognitive impairments. However, whether the elevated plasma APN levels reported in AD patients [44] was a compensatory mechanism for $\mathrm{AD}$ onset requires further investigation.

$\mathrm{A} \beta$ is believed to be one of the major neurotoxic species in AD pathogenesis. Our results have shown that soluble $A \beta$ peptide production was increased along with the present of $A \beta * 56$ (dodecamers) in APN-KO mice by 18-month. Unfortunately, low-molecular mass of mouse $\mathrm{A} \beta$ was hard to be detected by western blotting. We are the first group to show that $A \beta * 56$ can be detected in mice without APP transgene. $A \beta * 56$ is a specific oligomeric $A \beta$ species present at higher levels in aging individuals with normal cognition and patients with mild cognitive impairments than patients with $\mathrm{AD}$. This $\mathrm{A} \beta$ oligomeric species is positively correlated with Tau CP13 $\left(\mathrm{pTau}^{\mathrm{S} 202}\right)$ level and negatively correlated with synaptic proteins in $A D$ patients [36]. Injection of $A \beta * 56$ into healthy rat induced memory impairments suggesting this specific $A \beta$ oligomer species might initiate ageassociated memory impairments, and possibly the action was independent of neuronal loss but related to changes in synaptic functions [37]. It is observed that adiponectin level decreases in aging, hence delineating the molecular linkage between adiponectin and $A \beta * 56$ formation may elucidate the mechanism of aged-related memory decline and even the onset of AD.

Our results clearly suggest that APN has an important role in cognitive functions of mammals. The mechanisms underlying APN activity in the CNS are poorly understood. It has been shown that APN receptors are abundantly expressed in the mammalian brain and APN can enhance hippocampal neural stem cells by inducing p38MAPK and inhibiting GSK3 $\beta$ activities [26]. These two molecules are important intracellular mediators of insulin signaling. Substantial evidence demonstrated that GSK $3 \alpha / \beta$ activation led to AD pathologies including $A \beta$ oligomerization, Tau hyperphosphorylation and synaptic loss $[8,10,45]$. It is well characterized that APN stimulates the activation of AMPK in peripheral tissues to enhance phosphorylation of IRS-1 at tyrosine residues that increase $\mathrm{pAkt}^{\mathrm{S}}{ }^{73}$ levels. $\mathrm{pAkt}^{\mathrm{S} 473}$ can promote insulin-mediated inhibition of GSK3 $\beta$. Postmortem studies revealed the increase of pIRS-1 ${ }^{\mathrm{S} 616}$ and activated GSK3 $\beta$ in AD brains [1]. Here, we propose that APNAdipoR1-AMPK-induced insulin signaling activities may be important to protect aging brain from AD pathogenesis through GSK3 $\beta$ inhibition. These imply that APN is essential in enhancing cerebral insulin signaling to maintain normal cognitive functions. Future studies may be required to investigate if APN can regulate cerebral 


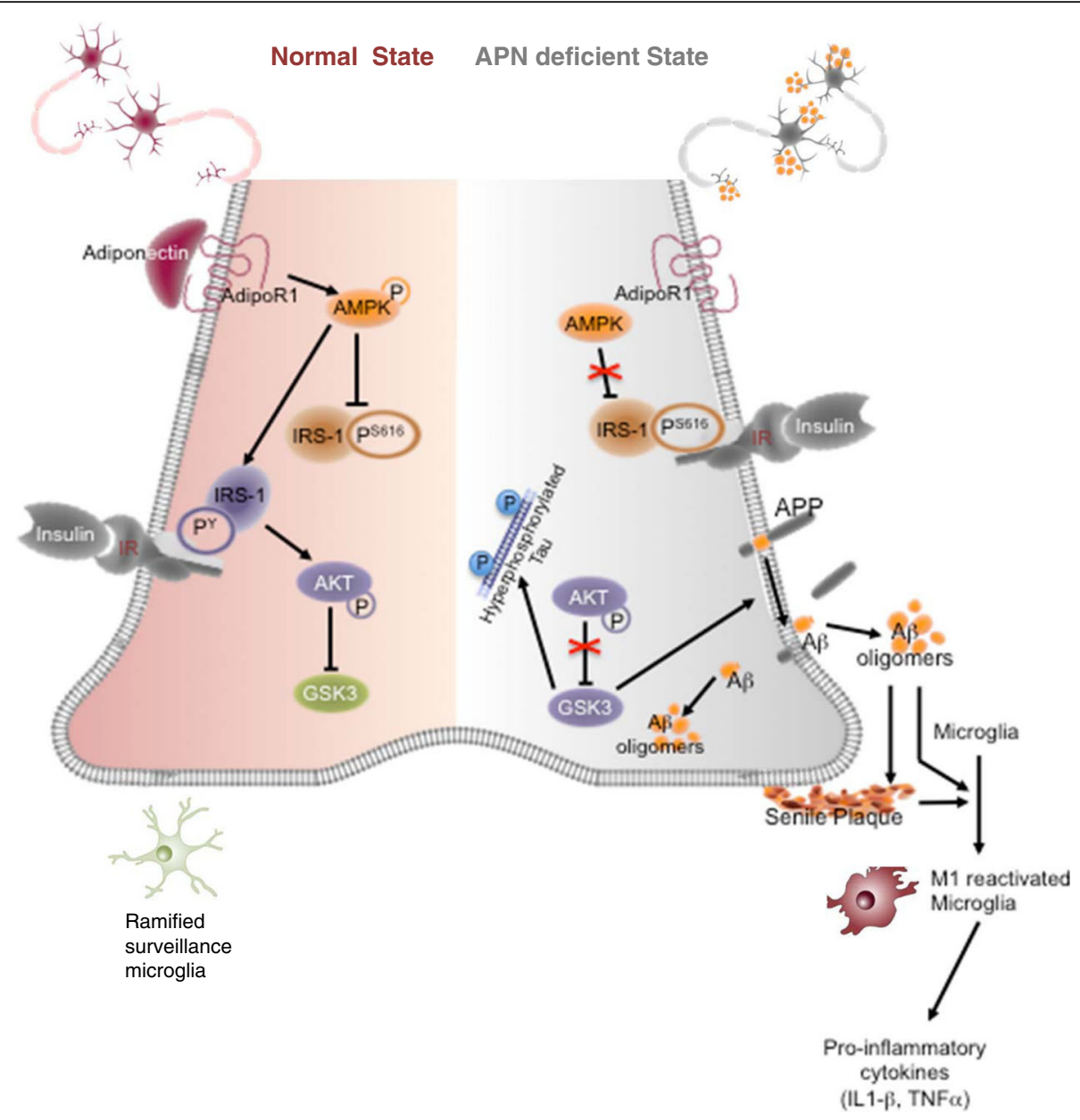

Fig. 7 Schematic presentation shows the Adiponectin signaling pathway in neuron under normal (left) and disease (right) conditions. We proposed that APN deficiency leads to decreased AMPK activation in neurons and increased IRS-1 phosphorylation at serine ${ }^{616}$ which inhibits the formation of pIRS-1 ${ }^{\text {Tyr }}$. Cerebral insulin resistance is progressively developed and thereby causing the reduced level of pAkt ${ }^{5473}$. The GSK3a/ $\beta$ become activated and may promote formation of $A \beta$ oligomers and Tau phosphorylation. The accumulation of extracellular A $\beta$ oligomers may induce M1 microglial reactivation and secretion of proinflammatory cytokines that associated with neuronal apoptosis and synaptic loss, and subsequently cognitive decline in aged APN-KO mice

glucose metabolism through p38MAPK activation or other insulin signaling responses.

We found that the insulin sensitivity was reduced by 9 months in the hippocampus and frontal cortex but were enhanced by 18 months in the hippocampus of $\mathrm{APN}-\mathrm{KO}$ mice. It is possible that some unknown compensatory mechanisms might have been activated in the hippocampal neurons. One of the possible mechanisms is the overexpression of insulin receptor (IR) in the hippocampus, but not in the frontal cortex, to enhance insulin signaling as observed in 18-mth-old APN-KO mice (Additional file 2: Figure S2a \& b). Overexpression of IR in the hippocampus may therefore induce Akt phosphorylation and inhibit GSK3. In addition to the Akt/GSK3 pathway, pErk1/2 was also increased solely in the hippocampus of 18-mth-old APN-KO mice. However, the improved insulin signaling could not reverse loss of synaptic proteins in aged APN-KO mice.
Therefore, we observed cognitive impairments in the 18-mth-old APN-KO mice.

Inflammation is not only crucial in body defense mechanism but is also playing critical roles in neurodegeneration and T2DM. TNF $\alpha$ levels are increased in subjects with obesity and T2DM. Several studies have demonstrated the presence of proinflammatory cytokines and reactivated microglia in AD brains [46-48]. In this study, we showed that the number of activated microglia was increased in APN-KO mice and both cerebral IL-1 $\beta$ and TNF $\alpha$ levels were increased. Surveillance microglia is responsible to recognize and remove extracellular $A \beta$ oligomers. $A \beta$ oligomers in the cortex and hippocampus of APN-KO mice may induce microglial activation, leading to secretion of the proinflammatory cytokines. We believe that APN might directly regulate the activation state of microglia. Though there is still no information on whether APN can regulate microglia 
activation, a recent report has demonstrated that microglia expressed adiponectin receptors. Osmotin, plant homolog of adiponectin, inhibited Toll-like receptor 4 (TLR4) in microglia cell line BV2 through AdipoR1 to prevent LPS-induced inflammation [49]. Moreover, astrocytes and macrophages also possess APN receptors and being stimulated by APN, suggesting that APN can regulate both cerebral and peripheral inflammation $[50,51]$. In addition to the increase of microglia-secreted cytokines, TNFa can also be secreted from adipocytes under APN deficient state or in APN-KO mice [42]. In contrast, increased APN production can suppress TNF $\alpha$ secretion from adipocytes [52]. Obese individuals and T2DM patients have increased TNF $\alpha$ levels in their circulation [53]. Plasma TNF $\alpha$ can cross the BBB and lead to cerebral insulin resistance by inhibiting IRS-1 phosphorylation at tyrosine residues $[1,6,11]$. Hence, peripheral inflammation due to chronic adiponectin deficiency may also contribute to $\mathrm{AD}$ pathologies.

\section{Conclusion}

In summary, the current study demonstrated that chronic APN deficiency might lead to cognitive decline and AD-like pathologies through insulin desensitization. It also raised the possibility that reduced CNS APN levels in T2DM and aging subjects could indeed be one of the causative factors of $\mathrm{AD}$ and cognitive impairment due to deregulated cerebral insulin signaling or cerebral insulin resistance. To our knowledge this is the first study to shed light on the role and molecular mechanism of APN on cognitive functions in mammals. This supports the use of adiponectin or adiponectin receptor agonists as target therapeutic agent in AD.

\section{Methods}

\section{Animal}

All mice were housed in a group of four to five per cage and maintained in the Laboratory Animal Unit of the University of Hong Kong. Mice were kept under $12 \mathrm{~h}$-lights on/12 h-dark cycle provided with free access food and water. Heterozygous adiponectin mutants on C57BL/6 N genetic background [54] were intercrossed to generate APN-KO mice and wildtype littermate controls. Tail DNA was collected for genotyping by PCR amplification. Detail primer sequences and PCR conditions were used as described previously [54]. All experiments were performed with male mice only. All procedures were approved by the Committee on the Use of Live Animals in Teaching and Research of the University of Hong Kong.

\section{Behavioral tests}

\section{Morris-Water-Maze test}

All mice that subjected to behavioral studies were male. APN-KO and WT mice of two age groups (9-months and 18 months) were assessed for spatial reference memory in the Morris Water Maze as described previously [55]. Mice were subjected to visible platform training for 2 consecutive days (4 trials per day) with different platform location in each trial. Hidden platform tasks were carried out in 6 consecutive days $24 \mathrm{~h}$ after the last visible test trial. Memory retention was assessed by three probe tests which were performed at the beginning of the 5th, 7th and 9th day before the training was started. The platform was removed and the time spent in the target quadrant was recorded. Mice were allowed to freely swim in $1 \mathrm{~min}$ and the distance traveled and percent time spent in each quadrant were recorded using a video tracking system (EthoVision 3.0, Noldus Information Technology, Leesburg, VA, USA).

\section{Open field test}

APN-KO and WT mice of two age groups (9-months and 18 months) were put into a transparent plastic $(26 \times 26 \times$ $40 \mathrm{~cm}^{3}$ ) box and was allowed to freely explore the field in a single 60-min session under dim light. The center area was defined as $10 \times 10 \mathrm{~cm}^{2}$ in the center of the open field. Parameters including the velocity, time in movement, time in the central/marginal zone, and average distance toward the zone border or field center were recorded and analyzed by video tracking system (EthoVision 3.0, Noldus Information Technology, Leesburg, VA, USA).

\section{Fear condition test}

The experimental procedures were followed as described previously [56]. In brief, mice were placed individually into a conditioning chamber $\left(25 \times 25 \times 25 \mathrm{~cm}^{3}\right)$ for $6 \mathrm{~min}$ of habituation in which the mice explored the context freely. This was followed by 3 pairs of conditioned stimulus (CS) $(30 \mathrm{~s}, 4 \mathrm{~Hz}, 80 \mathrm{~dB})$ and foot-shock which was applied to the floor grid of the chamber as the US $(2 \mathrm{~s}, 0.5 \mathrm{~mA})$. The inter-pair interval was $2 \mathrm{~min}$ with 2 min rest after the final CS pair. The chambers were cleaned with $70 \%$ alcohol between each training session. For contextual and cued tests, mice were placed at the same context for $8 \mathrm{~min}$ with no foot-shock and a new context with explicit cue in the absence of footshock respectively (Additional file 2). A video-tracking system EthoVision XT7 (Noldus, Wageningen, The Netherlands) was used for monitoring and recording throughout the training and memory test sessions. The videos were saved for later behavioral analysis.

\section{Intracerebral injection}

Mice were fasted overnight in cages and provided with free access of water. Mice were anesthetized by ketamine and xylazine, and then positioned in a stereotaxic frame. Deep anesthesia, breathing and body temperature were maintained throughout the surgical procedures. Mice 
were injected with insulin in a dose of 2 I.U $/ \mathrm{kg}$ body weight. The skull was exposed by incising the scalp. Craniotomy was performed with a drill at $(-2.5 \mathrm{~mm}$, $-2.2 \mathrm{~mm}$ ) from the bregma line and midline respectively. Stainless syringe (Hamilton, Reno, NV) was inserted into $2.1 \mathrm{~mm}$ depth, in which the position corresponding to the right hippocampus. $2.0 \mu \mathrm{l}$ of insulin solution or artificial cerebrospinal fluid (aCSF) was injected manually to the targeted tissue at a rate of $1.0 \mu \mathrm{l} / \mathrm{min}$. Needle was left in place for an additional $5 \mathrm{~min}$ to prevent liquid backflow. Mice were sacrificed and decapitated $30 \mathrm{~min}$ after injection. Brains were dissected out and the hippocampi were collected for immunoblotting analysis.

\section{Cell culture and RNAi transfection}

Human neuroblastoma cell line (SH-SY5Y) was used in this study. To establish insulin resistance neuroblastoma cells (SH-SY5Y IR), SH-SY5Y cells were pretreated with high concentration insulin $(1000 \mathrm{nmol} / \mathrm{L})$ for $48 \mathrm{~h}$ to induce intrinsic insulin resistance. Mammalian expressed trimeric Adiponectin $\left(\mathrm{APN}_{\mathrm{Tri}}\right)$ was purified as described before. For cell overexpressing APP mutant, SH-SY5Y cells was stably transfected with Swedish mutant of APP (sw-APP) and cultured in DMEM/F12 with $10 \% \mathrm{FBS}$ as described before [31]. Double sheath RNAi of scramble RNA, AdipoR1 and AdipoR2 were performed and the sequence of RNAi used as described previously [57]. Cells were pretreated with either $\mathrm{APN}_{\mathrm{Tri}}(10 \mu \mathrm{g} / \mathrm{mL})$ or Compound $\mathrm{C}$ (Calbiochem, USA) $1 \mathrm{~h}$ before culturing with $10 \mathrm{nmol} / \mathrm{L}$ insulin. Cells were collected and lysed for immunoblotting analysis. Culture medium was collected for ELISA after culturing cells with APN for $48 \mathrm{~h}$.

\section{$A \beta$ quantification}

Sandwich enzyme-linked immunosorbent assay (ELISA) was performed as described previously [58] by mouse Beta Amyloid 42 and human Beta Amyloid 42 ELISA kits (Thermo Fisher Scientific, US).

\section{CSF collection and dot blot immunoassay}

Mice were deeply anesthetized with Ketamine/Xylazine. CSF was withdrawn by glass capillary from the cisterna magna as described previously [59]. For Dot Blot immunoassay, $1 \mu \mathrm{l}$ of CSF was added onto a nitrocellulose membrane. Full length recombinant mouse Adiponectin protein was serially diluted and $1 \mu \mathrm{l}$ of the serial diluted protein was added on the nitrocellulose membrane for standard curve. Membrane was dried in air for $1 \mathrm{~h}$ at room temperature and blocked by $5 \%$ non-fat milk/ TBST. Membrane was then incubated with rabbit-antiadiponectin (1:1000; AIS HKU, HK) at room temperature for $1 \mathrm{~h}$ followed by $30 \mathrm{~min}$ HRP conjugated Goat- anti-rabbit IgG antibody. Signal was developed by Westernbright Quantum HRP substrate (advansta, USA).

\section{Cell lysis and immunoblotting}

For Immunoblotting, mice were sacrificed and decapitated. Brains were dissected on ice. Frontal cortex and hippocampi were collected and homogenized in lysis buffer by sonication. Homogenates were centrifuged at $12,000 \mathrm{~g}$ for $10 \mathrm{~min}$. Supernatants were aliquoted and kept at $-80{ }^{\circ} \mathrm{C}$. Protein concentration was determined by Bradford assay (Biorad, USA). $20 \mu \mathrm{g}$ of the cell homogenates were subjected to $10 \%$ SDS polyacrylamide gels and transferred onto polyvinylidene fluoride (PVDF) membrane. Immunoblotting was performed as described previously [60]. Primary antibodies including rabbit-antiIRS-1 ${ }^{\text {pS616 }}$ (Invitrogen, CA), mouse-anti-pGSK3 $\alpha^{\text {S21 }}$ (Cell Signaling Tech. Inc, USA), rabbit anti-GSK3 $\alpha$ (Cell Signaling Tech. Inc, USA), rabbit anti-pGSK3 $\beta^{\mathrm{S} 9}$ (Cell Signaling Tech. Inc, USA), rabbit anti-GSK3 $\beta$ (Cell Signaling Tech. Inc, USA), rabbit anti-Erk1/2 (Cell Signaling Tech. Inc, USA), rabbit-anti-pErk1/2 (Cell Signaling Tech. Inc, USA), rabbit-anti-pAkt ${ }^{\mathrm{S473}}$ (Cell Signaling Tech. Inc, USA), rabbit-anti-Akt (Cell Signaling Tech. Inc, USA), rabbit anti-AMPK (cell signaling Tech. Inc, USA), rabbit anti-pAMPK ${ }^{\mathrm{T} 172}$ (Cell Signaling Tech. Inc, USA), rabbit anti-IRS-1 (Cell Signaling Tech. Inc, USA), mouse anti-MHCII (AbDSerotec., UK), rabbit-anti-

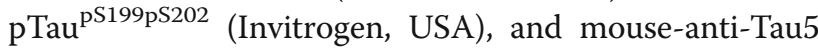
(Invitrogen, USA), mouse-anti-synaptophysin (Invitrogen, USA), and HRP-conjugated $\beta$-actin (Cell Signaling Tech. Inc, USA) were incubated at $4{ }^{\circ} \mathrm{C}$ overnight followed by stringent wash with TBS-Tween20. The PVDF membranes were incubated with HRP-conjugated secondary antibodies (goat anti-rabbit, 1:5000 or rabbit anti-mouse, 1:7000; Dako, Glostrup, Denmark).

\section{Tissues processing, immunohistochemistry and immunofluorescence staining}

For immunohistochemistry, mice were anesthetized with Ketamine/Xylazine. Dissected brains were fixed overnight in $4 \%$ paraformaldehyde at $4{ }^{\circ} \mathrm{C}$. Fixed brains were dehydrated in gradient ethanol followed by xylene and embedded in paraffin wax. Sections were rehydrated by graded ethanol to water. Antigens retrieval was performed by incubating sections with $10 \mathrm{mM}$ citrate buffer. Endogenous peroxidase was inactivated by hydrogen peroxide solution. Sections were incubated with primary antibodies, goat anti-GFAP (Santa Cruz, US), mouse monoclonal anti-A $\beta$ (4G8, Biolegend), and rabbit anti-Iba-1 (Wako, Japan) at $4{ }^{\circ} \mathrm{C}$ overnight. Sections were incubated with either rabbit anti-mouse or rabbit anti-goat (1:200; Dako, Glostrup, Denmark). Brown color staining was developed and counterstained with hematoxylin. Quantification of staining was performed 
as described previously [58, 61]. For immunofluorescent staining, sections were incubated with rabbit anti-AdipoR1 (ab70362, Abcam, UK) at $4{ }^{\circ} \mathrm{C}$ overnight, followed by Donkey anti-rabbit IgG Alexa Fluor ${ }^{\circ}$ 594-conjugated secondary antibody (Thermofisher, US) for 30 mins. Sections were mounted by slow fade ${ }^{\circ}$ anti-fade DAPI reagent (Lifetech, US).

\section{Thioflavin S staining}

Brain sections were deparaffinized by xylene followed by gradient ethanol treatments $(100,9570 \%, 50 \%)$ for 3 mins each. Sections were then incubated with $0.5 \%$ Thioflavin S in $50 \%$ ethanol for 30 min. Sections were then washed with 50\% ethanol and dehydrated with gradient ethanol. Sections were mounted by DPX reagent.

\section{Quantification of neuronal apoptotic cells}

To detect neuronal apoptotic cells, sections were treated with $0.1 \mathrm{M}$ citrate buffer at $90{ }^{\circ} \mathrm{C}(\mathrm{pH}$ 6.0) for antigen retrieval. TUNEL assay was used with an in-situ cell death detection kit (Roche, Mannheim, Germany) followed by incubating with mouse monoclonal primary anti-NeuN antibody (MAB377; Millipore, US) at $4{ }^{\circ} \mathrm{C}$ overnight. Sections were then incubated with donkey anti-mouse IgG Alexa Fluor ${ }^{\bullet}$ 594-conjugated secondary antibody (Thermofisher, US) for 30 mins. Sections were mounted by slow fade ${ }^{\circ}$ anti-fade DAPI reagent (Lifetech, US).

To quantify the degree of apoptotic cell death in the cortex and hippocampus, ten coronal sections from rostro-to-caudal region of the cortex and hippocampus were examined and TUNEL-positive cells were manually counted in a defined sampling region. One sampling region of interest from the hippocampal CA1 and two sampling regions in the cortex were defined. Only TUNEL-label cells colocalized with condensed nuclei staining were counted. The number of TUNEL-positive cells was the sum of apoptotic cell counts from all sample fields in the quantified sections of one embedded block. The number of TUNEL-positive cells reported was the mean of $n$ number in each group.

\section{Statistics}

Dot blot immunoassay, western blot data and immunohistochemistry staining were quantified by ImageJ and presented as group mean \pm S.E.M. Statistical analyses were performed by using unpaired Student $t$-test or one way ANOVAs followed by Newman-Keuls multiple comparison test. Behavioral tests data were analyzed by one-way ANOVA followed by Bonferroni's correction for multiple testing. Behavioral tests results were presented as mean \pm S.E.M with $p<0.05$ considered as statistically significant.

\section{Additional files}

Additional file 1: AdipoR1 expression in brain and dot-blot immunoassay of CSF adiponectin. (a) Immunofluorescent analysis of AdipoR1 in cortex and hippocampus of adult mouse. (b) Standard curve of full length mouse adiponectin (0-1000 ng/mL). (c) Representative dot-blot image of the serial diluted APN and CSF from 18-month old WT and APN-KO mice. (d) Dot-blot immunoassay of APN concentration in the CSF for both WT and APN-KO mice by 18 months. APN was undetectable in CSF of APN-KO mice. ${ }^{*} p<0.05$; WT $(n=4)$ vs APN-KO $(n=3)$. (JPG $57 \mathrm{~kb})$

Additional file 2: Behavioral Tests. (a) Swim speeds of WT and APN-KO mice by 9-months and 18 months in Morris-Water-Maze tests displayed no significant difference $(p>0.05)$ indicating the escape latency observed was not due to locomotor defects. (b) Study design of fear-conditioning contextual and cue tests. (JPG $33 \mathrm{~kb}$ )

Additional file 3: Selected frame of the contextual test for wildtype (left) and APN-KO (right) mice. APN-KO mice froze significantly less than wildtype mice. (MP4 $3153 \mathrm{~kb}$ )

Additional file 4: Selected frame of the cue test for wildtype (left) and APN-KO (right) mice. The clip includes first section of 30-s tone and 30-s rest afterwards. Tone starts at $0^{\prime \prime}$ and ends at $30^{\prime \prime}$ in the clip. APN-KO mice froze significantly less than wildtype mice. (MP4 $2612 \mathrm{~kb}$ )

Additional file 5: Representative immunoblotting analysis of the levels of insulin signaling effectors (pErk1/2, pGSK3a ${ }^{21}$, pGSK3a ${ }^{\text {Y279 }}$ ) in (a) 9-mth-old \& (b) 18-mth-old WT and APN-KO mice. Densitometric analysis of the ratio of

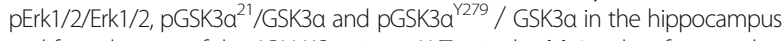
and frontal cortex of the APN-KO mice or WT mice by (c) 9-mths-of-age and (d) 18-mths-of-age. Mean \pm S.E.M.; ${ }^{*} p<0.05,{ }^{* *} p<0.01,{ }^{* * *} p<0.001$, n.s. statistically not significant; WT $(n=3)$ vs APN-KO ( $n=3$ or 4$)$. (JPG $72 \mathrm{~kb})$

Additional file 6: (a) Immunoblotting analysis of IR $\beta$ in the hippocampus and frontal cortex of 18-month old wildtype and APN-KO mice. (b) Densitometric analysis of the ratio of IR $\beta$. Mean \pm S.E.M.; ${ }^{* * *} p<0.001$, n.s. statistically not significant; Scale bar: $100 \mu \mathrm{m}$. (JPG $30 \mathrm{~kb}$ )

Additional file 7: Cerebral insulin injection to the right hippocampus. (a) $2 \mu \mathrm{l}$ of insulin (0.05I.U) or artificial cerebrospinal fluid were injected to the right hippocampus (coordination: $2.5 \mathrm{~mm}$ [D-V]; $2.2 \mathrm{~mm}[\mathrm{~A}-\mathrm{P}] ; 2.1 \mathrm{~mm}$ [Lateral] from Bregma) of 12-mth-old mice. (b) Trypan Blue dye was injected to the same coordination of the right hippocampus indicated successful injection. (JPG $35 \mathrm{~kb}$ )

Additional file 8: APN enhances insulin sensitivity in neuronal cells with insulin resistance. SH-SY5Y neuroblastoma cell pretreated with high concentration insulin $(1 \mu \mathrm{mol} / \mathrm{L})$ for $48 \mathrm{~h}$ to induce insulin resistance $\left(\mathrm{SH}-\mathrm{SY} 5 \mathrm{Y}_{\mathbb{R}}\right)$. Western blotting of pAMPK, pAkt and pGSK3 $\beta^{S 9}$ levels of the SH-SY5Y $\mathbb{I R}_{\mathrm{R}}$ cells that treated with $10 \mathrm{nmol} / \mathrm{L}$ insulin, $10 \mu \mathrm{g} / \mathrm{mL}$ APN $^{T r i}$ \& $10 \mathrm{nmol} / \mathrm{L}$ insulin with/without compound C (2 $\mu \mathrm{M})$ for $24 \mathrm{~h}$. (JPG $46 \mathrm{~kb}$ )

\section{Abbreviations}

Alzheimer's disease: AD; AMPK, APN: Adiponectin; Aß: Amyloid-beta; CSF: cerebrospinal fluid; ELISA: Enzyme-linked immunosorbent assay; Erk: Extracellular signal-regulated kinase; GFAP: Glial fibrillary acidic protein; GSK3: Glycogen synthase kinase 3; Iba-1: lonized calcium-binding adapter molecule 1; IL1 $\beta$ : Interleukin 1 $\beta$; IR: Insulin receptor; IRS-1: Insulin receptor substrate 1; MHC: Major histocompatibility complex; NeuN: Neuronal nuclear antigen; TNFa: Tumor necrosis factor alpha; TUNEL: Terminal deoxynucleotidyl transferase dUTP Nick end labeling; WT: Wildtype

\section{Acknowledgements}

We thank Antibody and Immunoassay Services, LKS Faculty of Medicine, HKU to provide recombinant adiponectin proteins for the experiments. We also thank Dr. Qi Li, Department of Psychiatry, HKU, for providing the set-up of Cue and Contextual fear-conditioning tests.

\section{Funding}

This project was supported by UGC Matching Fund for Donation towards Research on Neuroinflammation, funding support from the Strategy Research Theme (SRT) on Neuroscience, and small project funding (201409176174), The University of Hong Kong. 


\section{Availability of data and materials}

The datasets supporting the conclusions of this article are included within the article and its additional files.

\section{Author contributions}

R.C-L.N., performed most of the experiments, wrote the manuscript, conceived and designed the functional studies. O-Y.C. performed the MWM and OF tests. J.S-C.K. involved in $\mathrm{HC}$ and WB experiments. P.W-L.H. collected mice samples. K.K-Y.C. and R.L-C.H. prepared mice for experiments. L.L.Z. and P.K-K.Y. assisted behavioral tests and analysis. A.Z. reviewed experimental results and advised on direction of study. S.K.C. supervised cognitive functions test, provided advice and edited the manuscript. K.S-L.L. proposed the hypothesis that adiponectin exerts neuroprotection in AD and edited the manuscript. K-H.C. gave comments on the manuscript, conceived and designed the functional studies. All authors agreed the data and the final manuscript.

\section{Competing interests}

The authors declare that they have no competing interests.

\section{Consent for publication}

Not Applicable.

\section{Ethics approval}

This study was approved by the Committee on the Use of Live Animals in Teaching and Research (L.A.U.) of the University of Hong Kong.

\section{Author details}

'Department of Medicine, LKS Faculty of Medicine, The University of Hong Kong, Hong Kong, Special Administrative Region, China. ${ }^{2}$ Research Center of Heart, Brain, Hormone and Healthy Aging, LKS Faculty of Medicine, The University of Hong Kong, Hong Kong, Special Administrative Region, China. ${ }^{3}$ Hong Kong University Alzheimer's Disease Research Network, LKS Faculty of Medicine, The University of Hong Kong, Hong Kong, Special Administrative Region, China. ${ }^{4}$ Neuroimmunology and Neuroinflammation Research Laboratory, LKS Faculty of Medicine, The University of Hong Kong, Hong Kong, Special Administrative Region, China. ${ }^{5}$ School of Biomedical Sciences, LKS Faculty of Medicine, The University of Hong Kong, Hong Kong, Special Administrative Region, China. ' LKS Faculty of Medicine, The University of Hong Kong, Hong Kong, HKSAR, 8/F Department of Medicine, 21 Sassoon Road, Pofulam, China.

Received: 7 June 2016 Accepted: 9 November 2016 Published online: 25 November 2016

\section{References}

1. Talbot K, Wang H, Kazi H, Han L, Bakshi KP, Stucky A, Fuino RL, Kawaguchi KR, Samoyedny AJ, Wilson RS, Arvanitakis Z, Schneider J a, Wolf B a, Bennett $\mathrm{D}$ a, Trojanowski JQ, Arnold SE, Demonstrated brain insulin resistance in alzheimer's disease patients is assocaited with IGF-1 resisitance, IRS-1 dysregulation, and cogntive decline. J Clin Invest. 2012;122:1316-38.

2. Chen Y, Deng Y, Zhang B, Gong CX. Deregulation of brain insulin signaling in Alzheimer's disease. Neurosci Bull. 2014;30:282-94.

3. Yaffe K, Blackwell T, Kanaya A, Davidowitz N, Barrett-Connor E, Krueger K Diabetes, impaired fasting glucose, and development of cognitive impairment in older women. Neurology. 2004;63:658-63.

4. Mushtag G, Khan J, Kamal M. Biological mechanisms linking Alzheimer's disease and type-2 diabetes mellitus. CNS Neurol Disord Drug Targets. 2014; 13:1192-201.

5. Willette A a, Bendlin BB, Starks EJ, Birdsill AC, Johnson SC, Christian BT, Okonkwo OC, La Rue A, Hermann BP, Koscik RL, Jonaitis EM, Sager M a, Asthana S. Association of insulin resistance with cerebral glucose uptake in late middle-aged adults at risk for Alzheimer disease. JAMA Neurol. 2015:53792:1-8.

6. Felice FG De. Science in medicine Alzheimer's disease and insulin resistance: translating basic science into clinical applications. J Clin Invest. 2013;123:531-9.

7. Avrahami L, Farfara D, Shaham-Kol M, Vassar R, Frenkel D, Eldar-Finkelman H. Inhibition of glycogen synthase kinase-3 ameliorates $\beta$-amyloid pathology and restores lysosomal acidification and mammalian target of rapamycin activity in the alzheimer disease mouse model: In vivo and in vitro studies. J Biol Chem. 2013;288:1295-306.
8. Phiel CJ, Wilson CA, Lee VM, Klein PS. GSK-3 a regulates production of Alzheimer' s disease amyloid- b peptides. Nature. 2003;17(lane 2):435-40.

9. Son SM, Song H, Byun J, Park KS, Jang HC, Park YJ, Mook-Jung I. Altered APP processing in insulin-resistant conditions is mediated by autophagosome accumulation via the inhibition of mammalian target of rapamycin pathway. Diabetes. 2012;61:3126-38.

10. DaRocha-Souto B, Coma M, Pérez-Nievas BG, Scotton TC, Siao M, SánchezFerrer P, Hashimoto T, Fan Z, Hudry E, Barroeta I, Serenó L, Rodríguez M, Sánchez MB, Hyman BT, Gómez-Isla T. Activation of glycogen synthase kinase-3 beta mediates $\beta$-amyloid induced neuritic damage in Alzheimer's disease. Neurobiol Dis. 2012;45:425-37.

11. Bomfim TR, Forny-germano L, Sathler LB, Brito-moreira J, Houzel J, Decker H, Silverman M a, Kazi H, Melo HM, Mcclean PL, Holscher C, Arnold SE, Talbot K, Klein WL, Munoz DP, Ferreira ST, De Felice FG. An anti-diabetes agent protects the mousebrain from defective insulin signalingcaused by Alzheimer's diseaseassociated A $\beta$ oligomers. J Clin Invest. 2012;122:1339-53.

12. Gao C, Liu Y, Li L. New animal models of Alzheimer's disease that display insulin desensitization in the brain. Rev Neurosci. 2013;24:607-15.

13. Ramos-Rodriguez JJ, Ortiz O, Jimenez-Palomares M, Kay KR, Berrocoso E, Murillo-Carretero MI, Perdomo G, Spires-Jones T, Cozar-Castellano I, Lechuga-Sancho AM, Garcia-Alloza M. Differential central pathology and cognitive impairment in pre-diabetic and diabetic mice. Psychoneuroendocrinology. 2013;38:2462-75.

14. Grillo C, Piroli G, Lawrence R, Wrighten S, Green A, Wilson S, Sakai R, Kelly S, Wilson M, Molt D, Reagan L: Hippocampal Insulin Resistance Impairs Spatial Learning and Synaptic Plasticity. Diabetes. 2015;64:3927-36.

15. Adzovic L, Lynn AE, D'Angelo HM, Crockett AM, Kaercher RM, Royer SE, Hopp SC, Wenk GL. Insulin improves memory and reduces chronic neuroinflammation in the hippocampus of young but not aged brains. Jeuroinflammation. 2015;12:1-10.

16. Chen Y, Zhao Y, Dai C-L, Liang Z, Run X, labal K, Liu F, Gong C-X. Intranasal insulin restores insulin signaling, increases synaptic proteins, and reduces $A \beta$ level and microglia activation in the brains of 3xTg-AD mice. Exp Neurol. 2014;261:610-9.

17. Yamauchi T, Iwabu M, Okada-Iwabu M, Kadowaki T. Adiponectin receptors: a review of their structure, function and how they work. Best Pract Res Clin Endocrinol Metab. 2014;28:15-23.

18. Oh DK, Ciaraldi T, Henry RR. Adiponectin in health and disease. Diabetes Obes Metab. 2007:9:282-9.

19. Caselli C. Role of adiponectin system in insulin resistance. Mol Genet Metab. 2014;113:155-60.

20. Ruan $H$, Dong LQ. Adiponectin signaling and function in insulin target tissues. J Mol Cell Biol. 2016:8:1-40.

21. Anderson NJ, King MR, Delbruck $L$, Jolivalt CG. Role of insulin signaling impairment, adiponectin and dyslipidemia in peripheral and central neuropathy in mice. Dis Model Mech. 2014;7:625-33.

22. Cheng KKY, Lam KSL, Wang B, Xu A. Signaling mechanisms underlying the insulin-sensitizing effects of adiponectin. Best Pract Res Clin Endocrinol Metab. 2014:28:3-13.

23. Liu J, Guo M, Zhang D, Cheng S-Y, Liu M, Ding J, Scherer PE, Liu F, Lu X-Y. Adiponectin is critical in determining susceptibility to depressive behaviors and has antidepressant-like activity. Proc Natl Acad Sci. 2012;109:12248-53.

24. Thundyil J, Pavlovski D, Sobey CG, Arumugam TV. Adiponectin receptor signalling in the brain. Br J Pharmacol. 2012;165:313-27.

25. Kusminski CM, Mcternan PG, Schraw T, Kos K, O'Hare JP, Ahima R, Kumar $\mathrm{S}$, Scherer PE. Adiponectin complexes in human cerebrospinal fluid: distinct complex distribution from serum. Diabetologia. 2007:50:634-42.

26. Zhang D, Guo M, Zhang W, Lu X. Adiponectin stimulates proliferation of adult hippocampal neural stem/progenitor cells through activation of p38 mitogen-activated protein kinase (p38MAPK)/glycogen synthase kinase $3 \beta$ (GSK-3ß)/ $\beta$-catenin signaling cascade. J Biol Chem. 2011;12:44913-20.

27. Yau S-Y, Li A, Hoo RLC, Ching YP, Christie BR, Lee TMC, Xu A, So K-F. Physical exercise-induced hippocampal neurogenesis and antidepressant effects are mediated by the adipocyte hormone adiponectin. Proc Natl Acad Sci. 2014;2-7.

28. Mikesell R, Ryu J, Hsieh C, Cremasco V. Lack of adiponectin leads to increased lymphocyte activation and worse severity of a mouse model of multiple sclerosis. Eur J Immunol. 2013:43:2089-100.

29. Miao J, Shen LH, Tang YH, Wang YT, Tao MX, Jin KL, Zhao YJ, Yang GY. Overexpression of adiponectin improves neurobehavioral outcomes after focal cerebral ischemia in aged mice. CNS Neurosci Ther. 2013;19:969-77. 
30. Masaki T, Anan F, Shimomura T, Fujiki M, Saikawa T, Yoshimatsu H. Association between hippocampal volume and serum adiponectin in patients with type 2 diabetes mellitus. Metabolism. 2012;61:1197-200.

31. Chan KH, Lam KSL, Cheng OY, Kwan JSC, Ho PWL, Cheng KKY, Chung SK, Ho JWM, Guo VY, Xu A. Adiponectin is Protective against Oxidative Stress Induced Cytotoxicity in Amyloid-Beta Neurotoxicity. PLoS One. 2012;7: e52354

32. Yu Z, Li W, Hou D, Zhou L, Deng Y, Tian M, Feng X. Relationship between adiponectin gene polymorphisms and late-onset Alzheimer's disease. PLoS One. 2015;10:e0125186.

33. Khemka VK, Bagchi D, Bandyopadhyay K, Bir A, Chattopadhyay M, Biswas A, Basu D, Chakrabarti S. Altered serum levels of adipokines and insulin in probable Alzheimer's disease. J Alzheimer's Dis. 2014;41:1-9.

34. Teixeira AL, Diniz BS, Campos AC, Miranda AS, Rocha NP, Talib LL, Gattaz WF, Forlenza OV. Decreased levels of circulating adiponectin in mild cognitive impairment and alzheimer's disease. NeuroMolecular Med. 2013;15:115-21.

35. Une K, Takei Y a, Tomita N, Asamura T, Ohrui T, Furukawa K, Arai H. Adiponectin in plasma and cerebrospinal fluid in $\mathrm{MCl}$ and Alzheimer's disease. Eur J Neurol. 2011;18:1006-9.

36. Lesn SE, Sherman MA, Grant M, Kuskowski M, Schneider JA, Bennett DA, Ashe $\mathrm{KH}$. Brain amyloid-b oligomers in ageing and Alzheimer's disease. Brain. 2013;136:1383-98.

37. Koh MT, Kotilinek L, Kayed R, Glabe CG, Yang A, LETTERS A specific amyloid$\beta$ protein assembly in the brain impairs memory. Nat. 2006:440:352-7.

38. Combs CK, Karlo JC, Kao SC, Landreth GE. beta-Amyloid stimulation of microglia and monocytes results in TNFalpha-dependent expression of inducible nitric oxide synthase and neuronal apoptosis. J Neurosci. 2001;21:1179-88

39. Ferreira ST, Clarke JR, Bomfim TR, De Felice FG. Inflammation, defective insulin signaling, and neuronal dysfunction in Alzheimer's disease. Alzheimer's Dement. 2014;10(1 SUPPL):S76-83.

40. Wang C, Mao X, Wang L, Liu M, Wetzel MD, Guan KL, Dong LQ, Liu F. Adiponectin sensitizes insulin signaling by reducing p70 56 kinase-mediated serine phosphorylation of IRS-1. J Biol Chem. 2007;282:7991-6.

41. Kadowaki T, Yamauchi T, Kubota N, Hara K, Ueki K, Tobe K. Review series adiponectin and adiponectin receptors in insulin resistance, diabetes, and the metabolic syndrome. J Clin Invest. 2006;116:1784-92.

42. Maeda N, Shimomura I, Kishida K, Nishizawa H, Matsuda M, Nagaretani H, Furuyama N, Kondo H, Takahashi M, Arita Y, Komuro R, Ouchi N, Kihara S, Tochino Y, Okutomi K, Horie M, Takeda S, Aoyama T, Funahashi T, Matsuzawa Y. Diet-induced insulin resistance in mice lacking adiponectin/ ACRP30. Nat Med. 2002;8:731-7.

43. De Felice FG, Ferreira ST. Inflammation, defective insulin signaling, and mitochondrial dysfunction as common molecular denominators connecting type 2 diabetes to Alzheimer Disease. Diabetes. 2014;63:2262-72.

44. van Himbergen TM, Alexa SB, Ai M, Seshadri S, Otokozawa S, Au R, Thongtang N, Wolf PA, Schaefer EJ. Biomarkers for insulin resistance and inflammation and the risk for all-cause dementia and Alzheimer disease results from the framingham heart study. Arch Neurol. 2012;69:564-600.

45. Gao C, Hölscher C, Liu Y, Li L. GSK3: A key target for the development of novel treatments for type 2 diabetes mellitus and Alzheimer disease. Rev Neurosci. 2012;23:1-11.

46. Lue LF, Rydel R, Brigham EF, Yang LB, Hampel H, Murphy GM, Brachova L, Du Yan S, Walker DG, Shen Y, Rogers J. Inflammatory repertoire of Alzheimer's disease and nondemented elderly microglia in vitro. Glia. 2001;35:72-9.

47. Mosher Kl, Wyss-Coray T. Microglial dysfunction in brain aging and Alzheimer's disease. Biochem Pharmacol. 2014;88:594-604.

48. Lue LF, Walker DG, Rogers J. Modeling microglial activation in Alzheimer's disease with human postmortem microglial cultures. Neurobiol Aging. 2001:22:945-56

49. Badshah H, Ali T, Kim MO. Osmotin attenuates LPS-induced neuroinflammation and memory impairments via the TLR4/NFKB signaling pathway. Sci Rep. 2016;6:24493.

50. Wan Z, Mah D, Simtchouk S, Klegeris A, Little JP. Globular adiponectin induces a pro-inflammatory response in human astrocytic cells. Biochem Biophys Res Commun. 2014:446:37-42.

51. Mandal P, Pratt BT, Barnes M, Mcmullen MR, Nagy LE. Molecular mechanism for adiponectin-dependent $\mathrm{m} 2$ macrophage polarization link between the metabolic and innate immune activity of full-length adiponectin. J Biol Chem. 2011:286:13460-9.

52. Shibata R, Sato K, Pimentel DR, Takemura Y, Kihara S, Ohashi K, Funahashi T, Ouchi N, Walsh K. Adiponectin protects against myocardial ischemiareperfusion injury through AMPK- and COX-2-dependent mechanisms. Nat Med. 2005;11:1096-103.

53. Hotamisligil GS, Arner P, Caro JF, Atkinson RL, Spiegelman BM. Increased adipose tissue expression of tumor necrosis factor-alpha in human obesity and insulin resistance. J Clin Invest. 1995:95:2409-15.

54. Fayad R, Pini M, Sennello J a, Cabay RJ, Chan L, Xu A, Fantuzzi G. Adiponectin deficiency protects mice from chemically induced colonic inflammation. Gastroenterology. 2007;132:601-14.

55. Durairajan SSK, Liu L-F, Lu J-H, Chen L-L, Yuan Q, Chung SK, Huang L, Li X-S, Huang J-D, Li M. Berberine ameliorates $\beta$-amyloid pathology, gliosis, and cognitive impairment in an Alzheimer's disease transgenic mouse model. Neurobiol Aging. 2012;33:2903-19.

56. Zhou IY, Ding AY, Li Q, Mcalonan GM, Wu EX. Magnetic resonance spectroscopy reveals $\mathrm{N}$-acetylaspartate reduction in hippocampus and cingulate cortex after fear conditioning. Psychiatry Res Neuroimaging. 2012;204:178-83.

57. Kenneth KY, Karen SL. Adiponectin-Induced Endothelial Nitric Oxide Synthase Activation and ... 2007(May).

58. Zhou L, Chan KH, Chu LW, Kwan JSC, Song YQ, Chen LH, Ho PWL, Cheng OY, Ho JWM, Lam KSL. Plasma amyloid- $\beta$ oligomers level is a biomarker for Alzheimer's disease diagnosis. Biochem Biophys Res Commun. 2012;423: 697-702.

59. Liu L, Duff K. A technique for serial collection of cerebrospinal fluid from the cisterna magna in mouse. J Vis Exp. 2008;10-12.

60. Chan KH, Kwan JSC, Ho PWL, Ho SL, Chui WH, Chu a CY, Ho JWM, Zhang WY, Kung MHW. Aquaporin-4 water channel expression by thymoma of patients with and without myasthenia gravis. J Neuroimmunol. 2010;227: 178-84.

61. Gengler S, McClean PL, McCurtin R, Gault VA, Hölscher C. Val(8)GLP-1 rescues synaptic plasticity and reduces dense core plaques in APP/PS1 mice. Neurobiol Aging. 2012:33:265-76.

\section{Submit your next manuscript to BioMed Central and we will help you at every step:}

- We accept pre-submission inquiries

- Our selector tool helps you to find the most relevant journal

- We provide round the clock customer support

- Convenient online submission

- Thorough peer review

- Inclusion in PubMed and all major indexing services

- Maximum visibility for your research

Submit your manuscript at www.biomedcentral.com/submit 